\title{
Cuprous Cluster-Based Coordination Sheets as Photocatalytic Regulators to Activate Oxygen, Benzoquinone and Thianthrenium Salts
}

Huilin Huang, Xu Jing, * Bingwen Zhong, Changgong Meng and Chunying Duan*

State Key Laboratory of Fine Chemicals, Zhang Dayu College of Chemistry, Dalian

University of Technology Dalian, 116024, P. R. China

Corresponding Author

*Xu Jing E-mail: xjing@dlut.edu.cn

*Chunying DuanＥ-mail: cyduan@dlut.edu.cn

\section{Contents}

1. Experimental Section.

2. Single Crystal X-ray Crystallography.

3. Characterizations of Catalysts.

4. Catalysis Details.

5. References. 


\section{Experimental Section.}

\section{Materials and methods}

All substrates were used as received from commercial suppliers, unless otherwise stated.

Chemicals were purchased from Sigma-Aldrich, Chempur, TCI, or Alfa Aesar. Thianthrenium salts were synthesized based on reported literature. ${ }^{\mathrm{S} 1, \mathrm{~S} 2}{ }^{1} \mathrm{H}$ NMR data were collected on a Varian INOVA-600 MHz, Bruker Avance III $500 \mathrm{MHz}$, Vaian DLG400 MHz spectrometer at ambient temperature. FT-IR spectra were recorded as KBr pellets on JASCO FT/IR-430 spectrometer. The powder XRD diffractograms were obtained on a Rigaku D/Max-2400 X-ray diffractometer with a sealed Cu tube $(\lambda=$ $1.54178 \AA$ ). IR spectra were recorded as $\mathrm{KBr}$ pellets on a NEXUS instrument. Thermogravimetric analyses (TGA) were performed at a ramp rate of $10{ }^{\circ} \mathrm{C} / \mathrm{min}$ in a nitrogen flow with an SDTQ600 instrument. Confocal Laser Scanning Microscopy micrographs were collected by Olympus Fluoview FV1000 with $\lambda_{\mathrm{ex}}=488 \mathrm{~nm}$. Liquid UV-vis spectra were performed on a TU-1900 spectrophotometer. The solid UV-vis spectra were recorded on a Hitachi U-4100 UV-vis-NIR spectrophotometer. Liquid UV-Vis spectra were performed on a TU-1900 spectrophotometer. The solid fluorescent spectrum was measured on an Edinburgh FS920 instrument. The time-resolved luminescence spectrum was measured on an Edinburgh FLS920 spectrometer. Electron paramagnetic resonance (EPR) experiments were measured on Bruker E500 instrument, and the intensity was recorded at $100 \mathrm{~K}$.

Solid-state cyclic voltammograms were measured on a Zahner PP211 instrument and measurements were performed on a three-electrode system with the photocatalystcoated glassy carbon as the working electrode, Pt plate as the counter electrode, and an 
$\mathrm{Ag} / \mathrm{AgCl}$ as a reference electrode were used in aqueous solution of $\mathrm{Bu}_{4} \mathrm{NPF}_{6}$ at a scan rate of $100 \mathrm{mV} \mathrm{s}^{-1}$. The microstructure and morphology observations of samples were performed with transmission electron microscope (TEM) of Tecnai F30 operated at 300 $\mathrm{kV}$, scanning electron microscope (SEM) of HITACHI UHR FE-SEM SU8220.

\section{Preparation}

\section{(1) Preparation of compound $\mathrm{Cu}-\mathbf{T F T}$}

In a glass tube, $2 \mathrm{~mL} 30 \mathrm{mM} \mathrm{CuI} \mathrm{solution} \mathrm{in} \mathrm{acetonitrile} \mathrm{was} \mathrm{allowed} \mathrm{to} \mathrm{diffused} \mathrm{slowly}$ in to a solution $2 \mathrm{~mL} 15 \mathrm{mM}$ ligands TFT in dimethyl formamide (DMF) at room temperature, and the interlayer solvent was $9 \mathrm{~mL} \mathrm{DMF} /$ acetonitrile solution $(\mathrm{v} / \mathrm{v}=1 / 4)$. After three weeks, yellow massive crystals can be obtained at the bottom of the tube. Crystals suitable for X-ray structural analysis were obtained after filtration. Further desiccation process was conduct with supercritical carbon dioxide. Yield: 65\% (based on ligands TFT).

(2) Preparation of $\mathrm{Cu}-\mathbf{T F T} @ \mathbf{1 a}$

The crystal of $\mathrm{Cu}-\mathbf{T F T} @ 1$ a was obtained suitable for X-ray structural analysis by soaking $\mathrm{Cu}$-TFT in a acetonitrile solution containing phenylacetylene for 24 hours.

\section{(3) Preparation of $\mathrm{Cu}-\mathbf{T F T} @ 3 \mathbf{3 a}$}

The crystal of $\mathrm{Cu}$-TFT@3a was obtained suitable for X-ray structural analysis by soaking $\mathrm{Cu}$-TFT in a acetonitrile solution containing Indazole-3carboxylicacidmethylester for 24 hours.

Dye uptake experiment : The $\mathrm{Cu}-\mathbf{T F T}$ crystals were immersed in the methanol saturated solution of $2^{\prime}, 7^{\prime}$-dichlorofluorescein for 12 hours, and the crystals were thoroughly washed with methanol until the solution was clarified. 
Substrate encapsulation experiments: The substrate-impregnated crystals were obtained by soaking crystals of $\mathrm{Cu}-\mathbf{T F T}$ in a solution of the substrate in acetonitrile (2 M) for $12 \mathrm{~h}$. After the soaked crystals was washed with acetonitrile, the substrate-loaded crystals were directly used for IR and digested with DMSO-d 6 , and the amounts of released substrate molecules were quantified by ${ }^{1} \mathrm{H}$ NMR.

EPR detection of aryl radical: The ROS generated by $\mathrm{Cu}$-TFT have been detected by EPR in the presence of TEMP, respectively. Typically, $20 \mu \mathrm{L}$ TEMP in $1 \mathrm{~mL}$ $\mathrm{CH}_{3} \mathrm{CN}$ was mixed with $0.5 \mathrm{~mL}$ of $\mathrm{Cu}-\mathbf{T F T} / \mathrm{CH}_{3} \mathrm{CN}$ suspension $(1 \mathrm{mg} / \mathrm{mL})$. The formed mixture $(400 \mu \mathrm{L})$ was added into the EPR tube.

The EPR measurements were carried out with $2 \mathrm{mg} \mathrm{Cu}$-TFT or $2 \mathrm{mg} \mathrm{Cu}$-TFT @3a@4a at $100 \mathrm{~K}$ under air atmosphere. To verify the PET process, we have tested the spectra of $\mathrm{Cu}-\mathbf{T F T}$ and $\mathrm{Cu}-\mathbf{T F T} @ 3 \mathbf{3 a} @ \mathbf{4 a}$ under the irradiation of white light and without light, respectively.

Photoelectrochemical Measurements: Through CHI 760E electrochemical workstation, photocurrent was measured in a standard three-electrode system with the photocatalyst-coated FTO as the working electrode, Pt plate as the counter electrode and $\mathrm{Ag} / \mathrm{AgCl}$ as the reference electrode. A $300 \mathrm{~W}$ xenon lamp with cutoff filter $(\lambda>$ $400 \mathrm{~nm}$ ) was used as light source. A $3 \mathrm{M} \mathrm{KCl}$ solution was used as electrolyte. The catalyst ( $2 \mathrm{mg}$ ) was added into a mixed solution with $20 \mu \mathrm{L}$ of $5 \mathrm{wt} \%$ Nafion and $1 \mathrm{~mL}$ of ethanol, and the working electrodes were prepared by dropping the suspension (100 $\mu \mathrm{L}$ ) onto the surface of a FTO plate with an area of $1 \mathrm{~cm}^{2}$. 


\section{Single Crystal X-ray Crystallography}

The intensities were collected on a Bruker SMART APEX CCD diffractometer equipped with a graphite-monochromated Mo K $\alpha(\lambda=0.71073 \AA)$ radiation source; the data were acquired using the SMART and SAINT programs. ${ }^{\mathrm{S} 3, \mathrm{~S} 4}$ The structure was solved by direct methods and refined by full matrix least-squares methods by the program SHELXL-2014. ${ }^{\text {S5 }}$

In the structural refinement of $\mathrm{Cu}$-TFT, all of the non-hydrogen atoms were refined anisotropically. The hydrogen atoms within the ligand backbones were fixed geometrically at calculated distances and allowed to ride on the parent non-hydrogen atoms. The SQUEEZE subroutine in PLATON was used. ${ }^{\mathrm{S} 6}$ 
Table S1. Crystal data and structure refinements.

\begin{tabular}{|c|c|c|}
\hline Compound & $\mathrm{Cu}-\mathbf{T F T}$ & Cu-TFT@1a \\
\hline Empirical formula & $\mathrm{C}_{48} \mathrm{H}_{48} \mathrm{Cu}_{4} \mathrm{I}_{4} \mathrm{~N}_{20} \mathrm{~S}_{6}$ & $\mathrm{C}_{61.5} \mathrm{H}_{58.5} \mathrm{Cu}_{4} \mathrm{I}_{4} \mathrm{~N}_{18.5} \mathrm{O}_{7.5} \mathrm{~S}_{6}$ \\
\hline Formula weight & 1859.37 & 2130.88 \\
\hline Temperature/K & 293(2) & 110 \\
\hline Crystal system & Trigonal & Trigonal \\
\hline Space group & $\mathrm{R}-3 \mathrm{c}$ & $\mathrm{R}-3 \mathrm{c}$ \\
\hline $\mathrm{a} / \AA$ & $20.619(5)$ & $20.5000(3)$ \\
\hline $\mathrm{b} / \AA$ & $20.619(5)$ & $20.5000(3)$ \\
\hline $\mathrm{c} / \AA$ & $90.454(5)$ & $87.071(3)$ \\
\hline$\alpha /^{\circ}$ & 90 & 90 \\
\hline$\beta /{ }^{\circ}$ & 90 & 90 \\
\hline$\gamma /{ }^{\circ}$ & 120 & 120 \\
\hline Volume $/ \AA^{3}$ & $33304(16)$ & $31689.2(14)$ \\
\hline $\mathrm{Z}$ & 11.9988 & 12 \\
\hline$\rho_{\text {cald }} / \mathrm{g} \cdot \mathrm{cm}^{-3}$ & 1.112 & 1.340 \\
\hline$\mu / \mathrm{mm}^{-1}$ & 2.011 & 2.127 \\
\hline $\mathrm{F}(000)$ & 10800.0 & 12492.0 \\
\hline Crystal size $/ \mathrm{mm}^{3}$ & $0.02 \times 0.02 \times 0.02$ & $0.02 \times 0.02 \times 0.02$ \\
\hline Radiation & $\operatorname{MoK} \alpha(\lambda=0.71069)$ & $\operatorname{MoK} \alpha(\lambda=0.71073)$ \\
\hline $\begin{array}{c}2 \text { theta range for data } \\
\text { collection } /{ }^{\circ}\end{array}$ & 4.176 to 49.998 & 4.684 to 56.174 \\
\hline Index ranges & $\begin{array}{c}-24 \leq \mathrm{h} \leq 18,-19 \leq \mathrm{k} \leq 24 \\
-107 \leq 1 \leq 107\end{array}$ & $\begin{array}{c}-27 \leq \mathrm{h} \leq 27,-27 \leq \mathrm{k} \leq 27 \\
-115 \leq 1 \leq 115\end{array}$ \\
\hline Reflections collected & 68153 & 138960 \\
\hline Independent reflections & $\begin{array}{c}4886\left[R_{\text {int }}=0.0773, R_{\text {sigma }}\right. \\
=0.0385]\end{array}$ & $\begin{array}{c}4886\left[R_{\text {int }}=0.0724, R_{\text {sigma }}\right. \\
=0.0303]\end{array}$ \\
\hline Data/restraints/parameters & $6534 / 6 / 247$ & $8593 / 202 / 309$ \\
\hline Goodness-of-fit on $F^{2}$ & 1.080 & 1.130 \\
\hline Final $\mathrm{R}$ indexes $[\mathrm{I}>=2 \sigma(\mathrm{I})]$ & $\mathrm{R}_{1}=0.0522, \mathrm{wR}_{2}=0.1550$ & $\mathrm{R}_{1}=0.0649, \mathrm{wR}_{2}=0.1954$ \\
\hline Final R indexes [all data] & $\mathrm{R}_{1}=0.0695, \mathrm{wR}_{2}=0.1602$ & $\mathrm{R}_{1}=0.0836, \mathrm{wR}_{2}=0.2092$ \\
\hline Largest diff. peak/hole / e $\AA^{-3}$ & $1.90 /-1.65$ & $1.72 /-1.49$ \\
\hline CCDC number & 2094866 & 2094867 \\
\hline
\end{tabular}


Table S2. Crystal data and structure refinements.

\begin{tabular}{|c|c|}
\hline Compound & Cu-TFT@3a \\
\hline Empirical formula & $\mathrm{C}_{57} \mathrm{H}_{56} \mathrm{Cu}_{4} \mathrm{I}_{4} \mathrm{~N}_{22} \mathrm{O}_{2} \mathrm{~S}_{6}$ \\
\hline Formula weight & 2035.35 \\
\hline Temperature/K & 200 \\
\hline Crystal system & Trigonal \\
\hline Space group & $\mathrm{R}-3 \mathrm{c}$ \\
\hline $\mathrm{a} / \AA ̊$ & $20.7951(6)$ \\
\hline $\mathrm{b} / \AA$ & $20.7951(6)$ \\
\hline $\mathrm{c} / \AA$ & $93.704(6)$ \\
\hline$\alpha /^{\circ}$ & 90 \\
\hline$\beta /^{\circ}$ & 90 \\
\hline$\gamma /{ }^{\circ}$ & 120 \\
\hline Volume $/ \AA^{3}$ & $35092.2(3)$ \\
\hline $\mathrm{Z}$ & 12 \\
\hline$\rho_{\text {calc }} / \mathrm{g} \cdot \mathrm{cm}^{-3}$ & 1.156 \\
\hline$\mu / \mathrm{mm}^{-1}$ & 1.916 \\
\hline $\mathrm{F}(000)$ & 11904.0 \\
\hline Crystal size $/ \mathrm{mm}^{3}$ & $0.02 \times 0.02 \times 0.02$ \\
\hline Radiation & $\operatorname{MoK} \alpha(\lambda=0.71073)$ \\
\hline $\begin{array}{l}2 \text { theta range for data } \\
\text { collection }^{\circ}\end{array}$ & 4.606 to 49.998 \\
\hline Index ranges & $\begin{array}{c}-24 \leq \mathrm{h} \leq 24,-21 \leq \mathrm{k} \leq 24 \\
-73 \leq 1 \leq 111\end{array}$ \\
\hline Reflections collected & 60803 \\
\hline Independent reflections & $\begin{array}{c}4886\left[\mathrm{R}_{\text {int }}=0.0641, \mathrm{R}_{\text {sigma }}\right. \\
=0.0376]\end{array}$ \\
\hline Data/restraints/parameters & $6876 / 397 / 374$ \\
\hline Goodness-of-fit on $F^{2}$ & 1.070 \\
\hline Final $R$ indexes $[\mathrm{I}>=2 \sigma(\mathrm{I})]$ & $\mathrm{R}_{1}=0.0713, \mathrm{wR}_{2}=0.2151$ \\
\hline Final R indexes [all data] & $\mathrm{R}_{1}=0.0844, \mathrm{wR}_{2}=0.2247$ \\
\hline Largest diff. peak/hole / e $\AA^{-3}$ & $1.19 /-2.76$ \\
\hline CCDC number & 2094868 \\
\hline
\end{tabular}




\section{Characterizations of Catalysts}

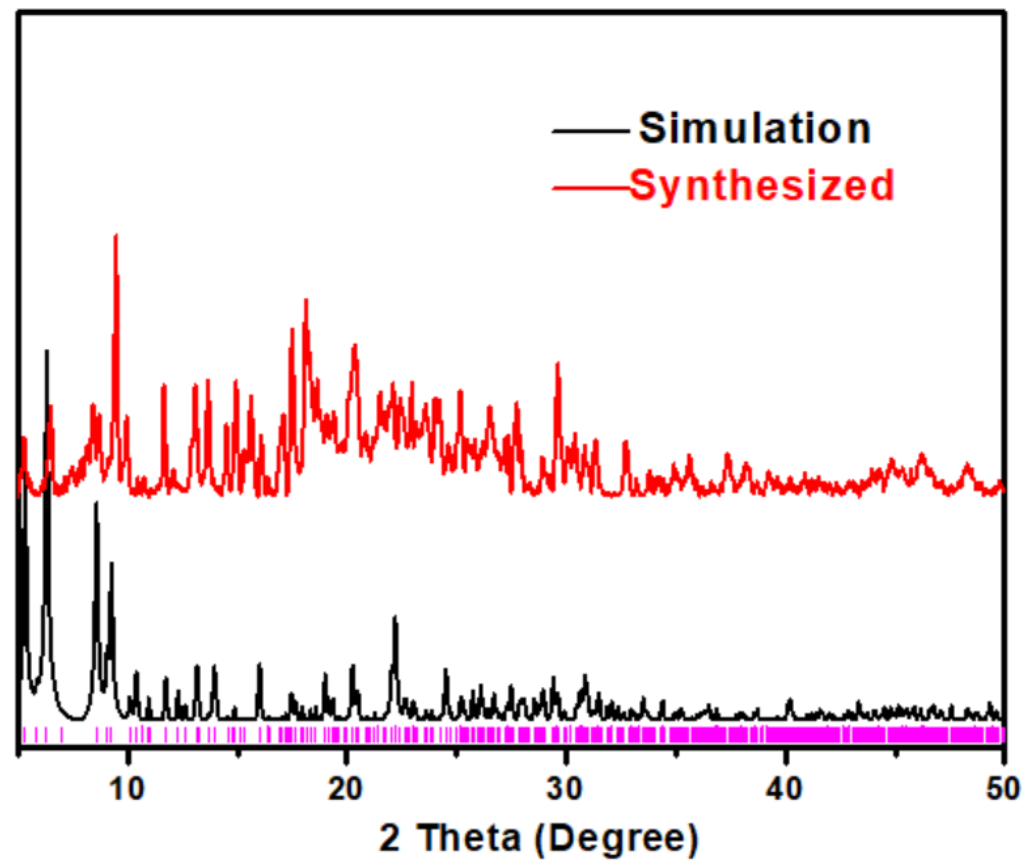

Figure S1. PXRD patterns of $\mathrm{Cu}$-TFT (red) and its calculated pattern based on the single-crystal simulation (black).

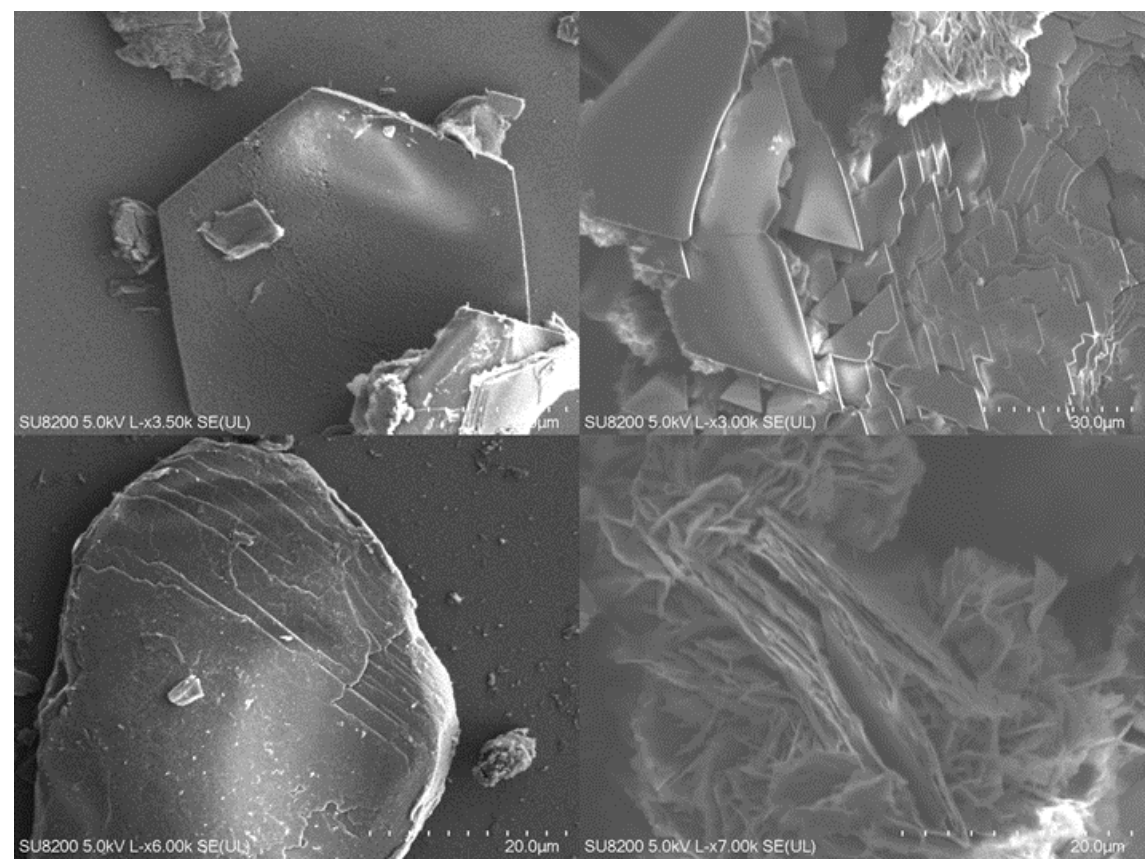

Figure S2. SEM images of the initial crystals (the original synthetic crystal without any treatment) $\mathrm{Cu}-\mathbf{T F T}$. 


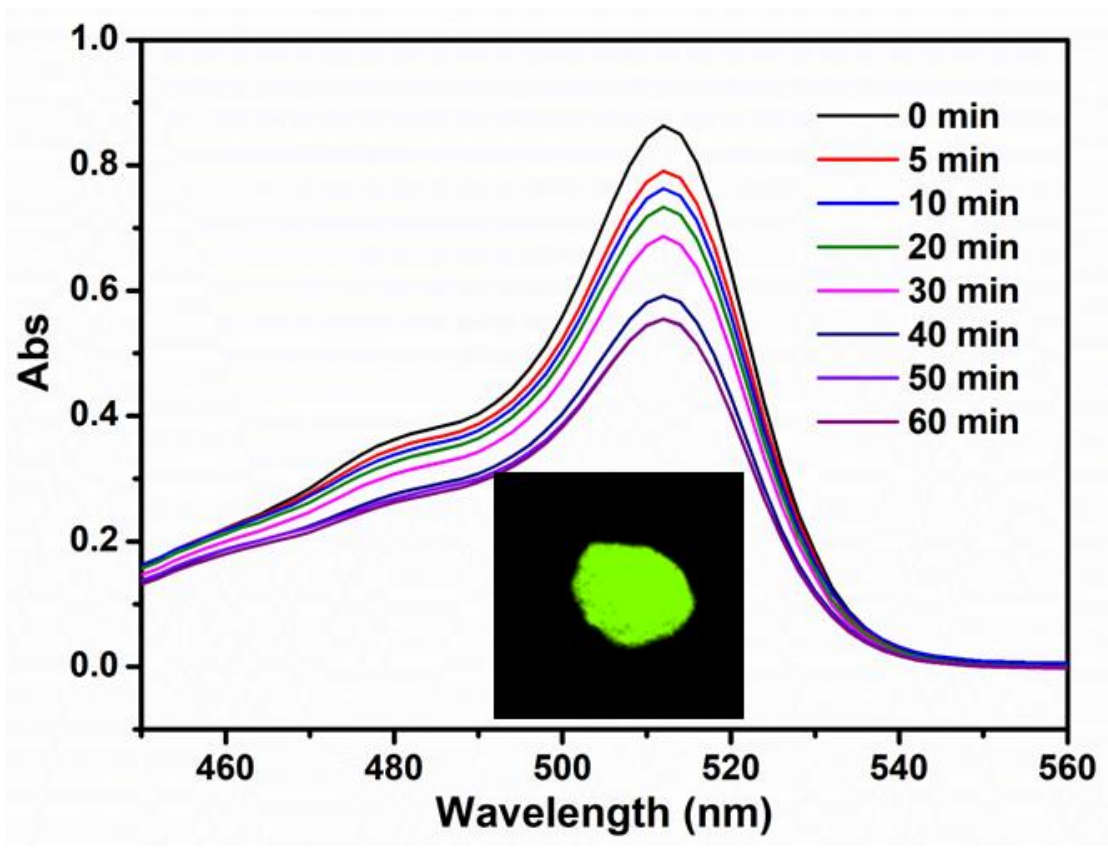

Figure S3. UV-vis measurements of the methanol solution of $2^{\prime}, 7^{\prime}$-dichlorofluorescein after adsorption by activated $\mathrm{Cu}$-TFT at different times and with the confocal image of 2', 7'- dichlorofluorescein-soaked $\mathrm{Cu}-$ TFT detected at $\lambda_{\mathrm{em}}=510-610 \mathrm{~nm}$, excited by $\lambda_{\text {ex }}=488 \mathrm{~nm}$ through a $405 / 488 \mathrm{~nm}$ filter as inset. The adsorption amount $q_{t}(\mathrm{mg})$ at time $t$ (min) was calculated as follows: $q_{t}=\left(C_{0}-C_{t}\right) * V$, where $C_{0}, C_{t}\left(\mathrm{mg}^{*} \mathrm{~L}^{-1}\right)$ were the dye concentrations at the initial $\left(30 \mathrm{mg}^{*} \mathrm{~L}^{-1}\right)$, any time $\mathrm{t}$, respectively. $V(0.05 \mathrm{~L})$ was the volume of the dye solution and $\mathrm{m}(10 \mathrm{mg})$ was the mass of $\mathrm{Cu}-$ TFT. $C_{0}$ was determined prior to the adsorption by measuring the amount of dye to be added. $C_{t}=$ $\left(A_{t} / A_{0}\right) * C_{0}, A_{0}, A_{t}$ were the dye absorbance at the initial $(0.8629)$, any time $\mathrm{t}$, respectively. ${ }^{\text {S7 }}$ The adsorption amount of $2^{\prime}, 7^{\prime}$-dichlorofluorescein based on the crystal weight $(\mathrm{R})$ was calculated as follows: $\mathrm{R}=\left(q_{t} / \mathrm{m}\right) * 100 \%$. 


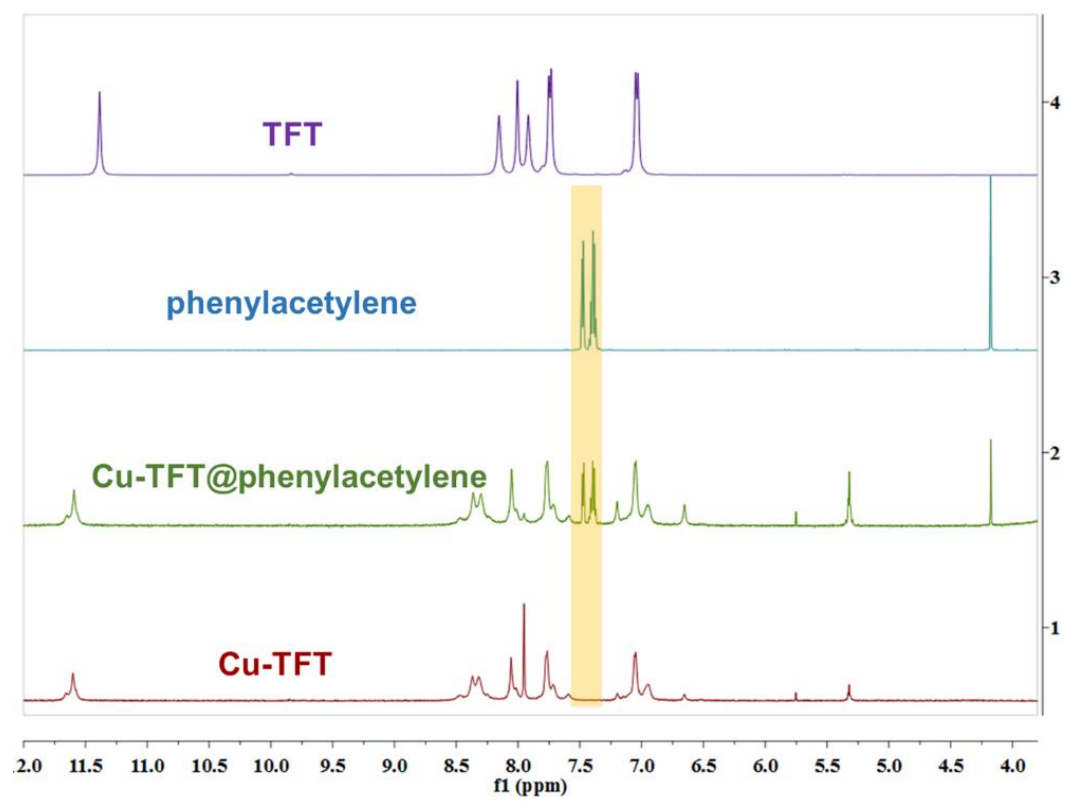

Figure S4. ${ }^{1} \mathrm{H}$ NMR spectra of the crystals of TFT, phenylacetylene, $\mathrm{Cu}-\mathbf{T F T}$ and $\mathrm{Cu}-$ TFT@ phenylacetylene (digested in DMSO- $\mathrm{d}_{6}$ ).

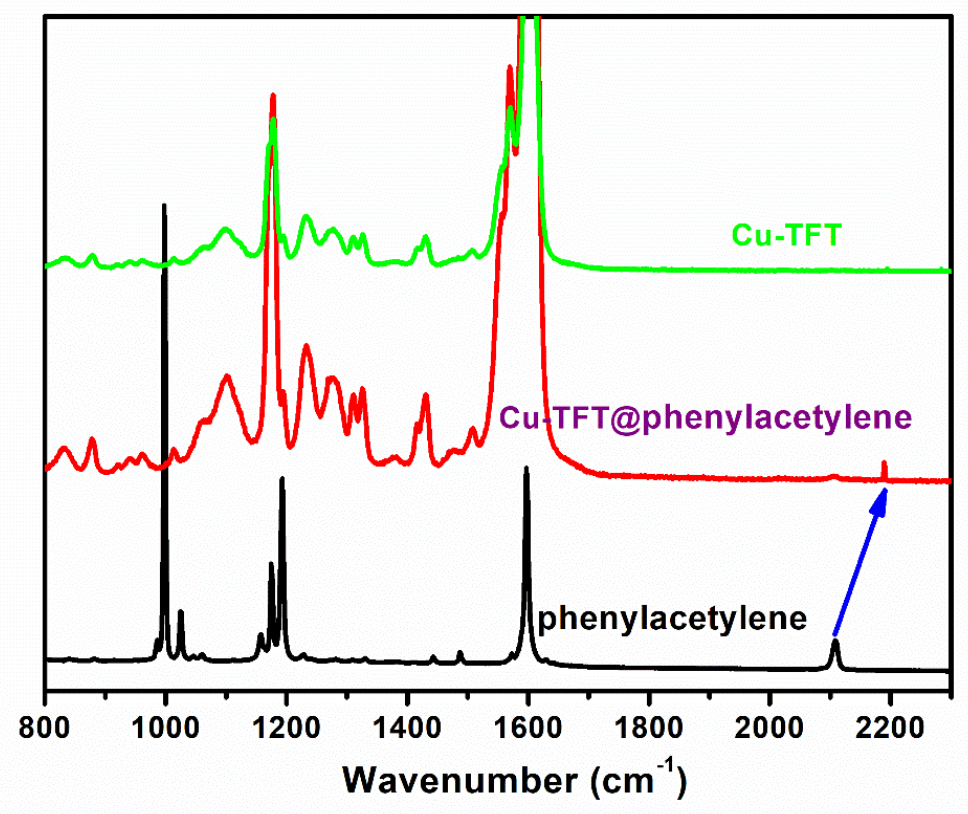

Figure S5. Raman spectra of $\mathrm{Cu}$-TFT, $\mathrm{Cu}$-TFT@phenylacetylene and phenylacetylene. (Raman spectroscopy (Lab Raman HR Evolution) measurements were performed using a solid state $633 \mathrm{~nm}$ laser and a laser power of $25 \%$ was used.) 


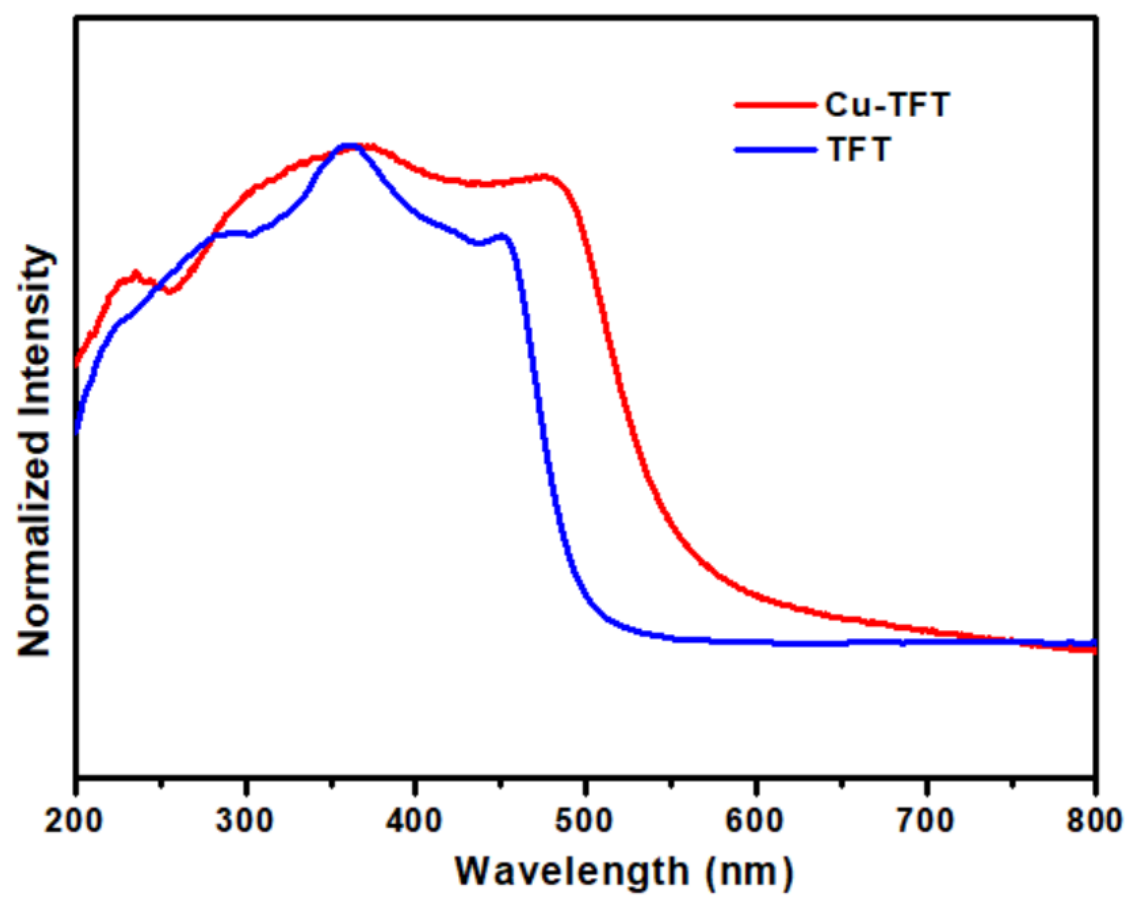

Figure S6 Solid UV-vis spectra of $\mathrm{Cu}$-TFT and the free ligand.

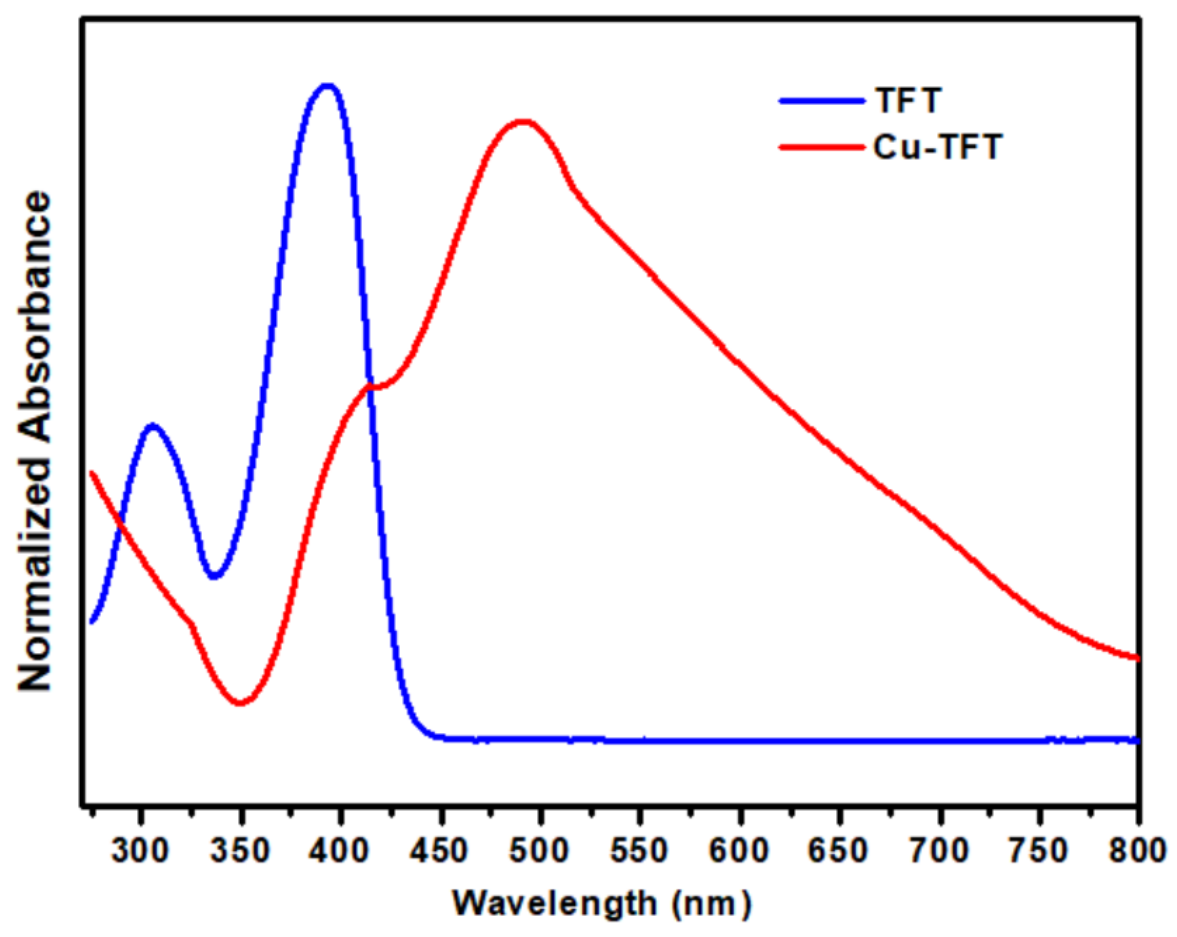

Figure S7 UV-vis absorption spectra of TFT and $\mathrm{Cu}$-TFT in $\mathrm{CH}_{3} \mathrm{CN}$ suspension. 


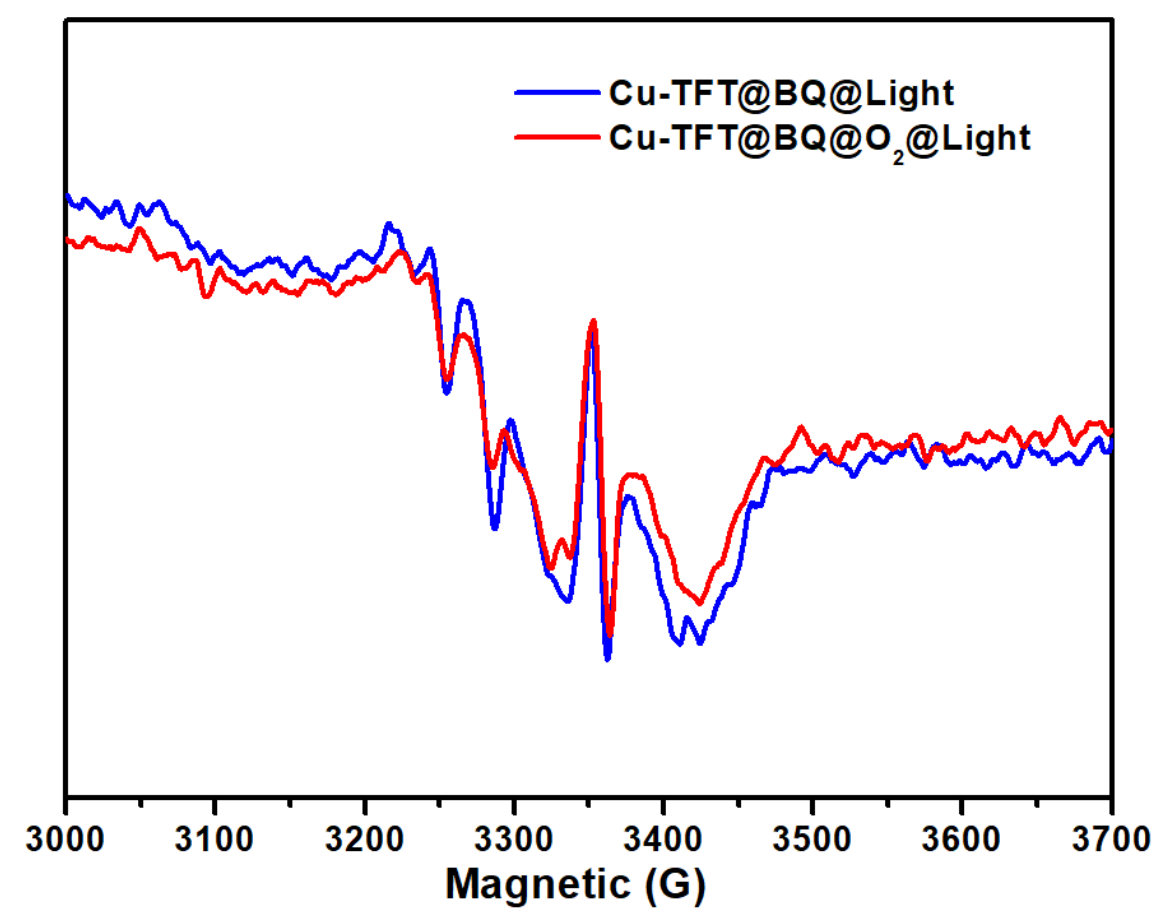

Figure S8 EPR of $\mathrm{Cu}$-TFT@BQ under the light irradiation with $\mathrm{O}_{2}$ (red line) or without (blue line).
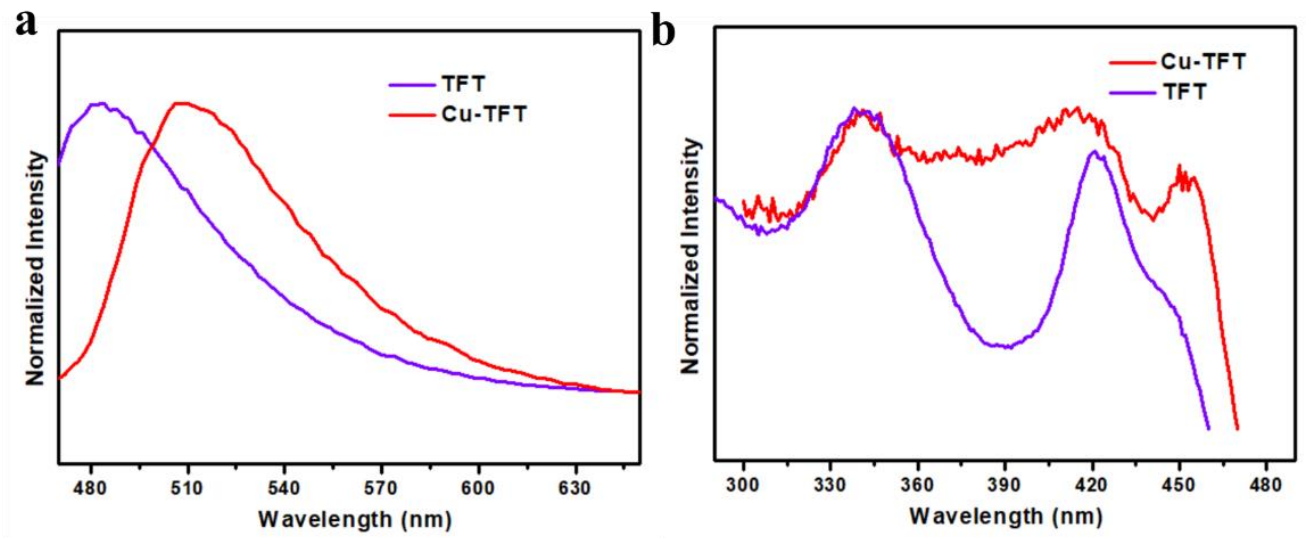

Figure S9. (a) Fluorescence emission spectra of TFT (purple line, $\lambda_{\mathrm{ex}}=450 \mathrm{~nm}$ ) and $\mathrm{Cu}$-TFT (red line $\lambda_{\mathrm{ex}}=450 \mathrm{~nm}$ ) suspension in acetonitrile; (b) Fluorescence excitation spectra of TFT (purple line, $\lambda_{\mathrm{em}}=486 \mathrm{~nm}$ ) and $\mathrm{Cu}-$ TFT (red line $\lambda_{\mathrm{em}}=510 \mathrm{~nm}$ ) suspension in acetonitrile. 


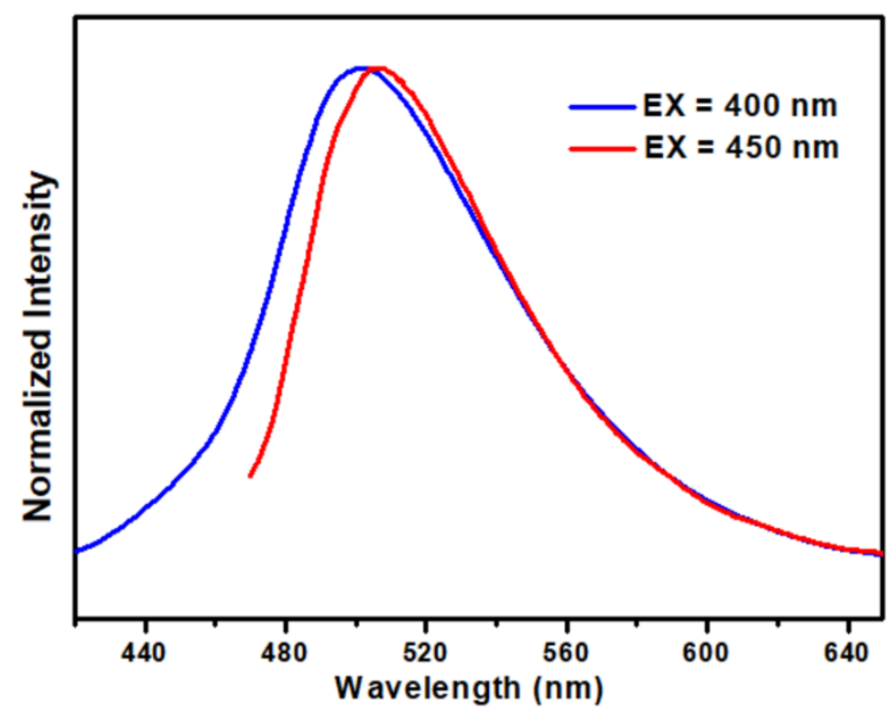

Figure S10. Fluorescence emission spectra of $\mathrm{Cu}-\mathbf{T F T}\left(\right.$ red line $\lambda_{\mathrm{ex}}=450 \mathrm{~nm}$, blue line $\left.\lambda_{\mathrm{ex}}=400 \mathrm{~nm}\right)$ suspension in acetonitrile.
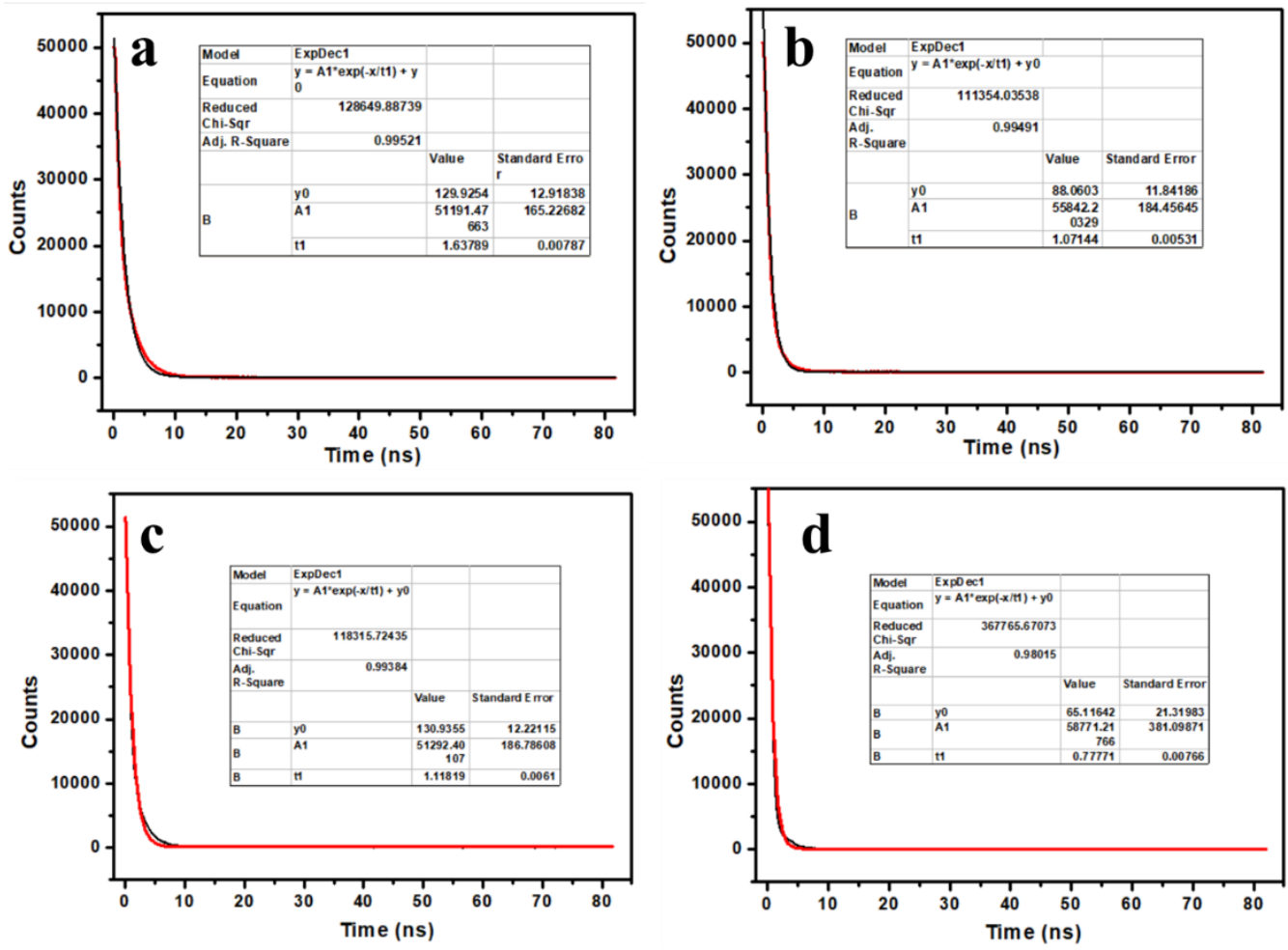

Figure S11. Luminescence decays of $\mathrm{Cu}-\mathbf{T F T}$ (a), Cu-TFT@BQ (b) and $\mathrm{Cu}-$ TFT@4a (c) suspensions in acetonitrile at $510 \mathrm{~nm}$, the suspensions were evacuated and backfilled with nitrogen for 3 cycles; (d) Luminescence decay of $\mathrm{Cu}$-TFT suspension in acetonitrile in $\mathrm{O}_{2}$. 

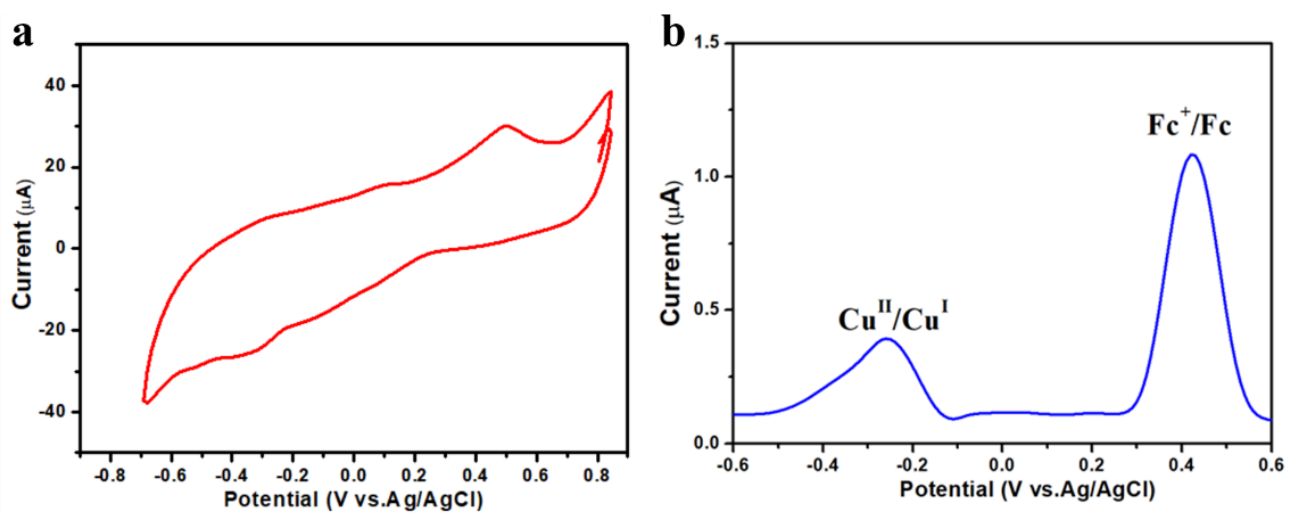

Figure S12. (a) Solid-state cyclic voltammogram of TFT. (b) Solid-state differential pulse voltammetry (DPV) of $\mathrm{Cu}$-TFT measured in acetonitrile with the ferrocene $(\mathrm{Fc})$ as the internal standard. Scan rate $0.1 \mathrm{~V} / \mathrm{s}$, working electrode: carbon-paste electrode; reference electrode: $\mathrm{Ag} / \mathrm{AgCl}$ electrode; counter electrode: a platinum-wire; electrolyte: 0.1 $\mathrm{MBu}_{4} \mathrm{NPF}_{6}$. The $\mathrm{E}_{1 / 2}\left(\mathrm{Cu}^{\mathrm{II}} / \mathrm{Cu}^{\mathrm{I}}\right)=-0.26 \mathrm{~V}$ vs. $(\mathrm{Ag} / \mathrm{AgCl})$.

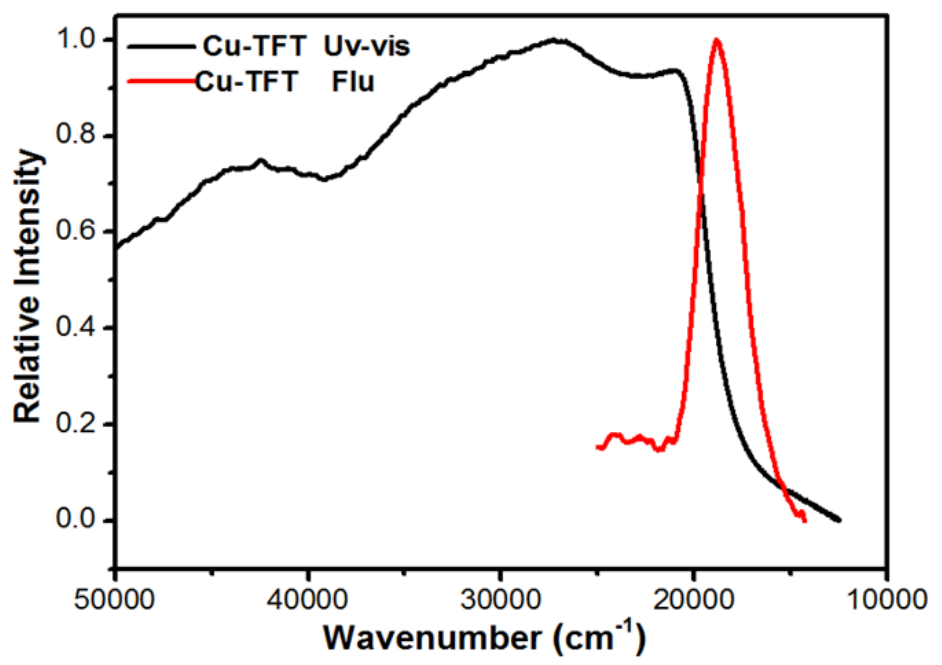

Figure S13. Normalized absorption and emission spectra of $\mathrm{Cu}-$ TFT $\left(\mathrm{E}^{0-0}=2.02 \mathrm{eV}\right)$.

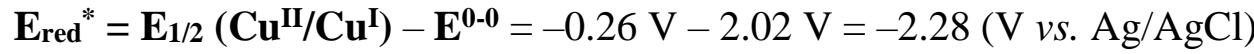

The Methods of Calculation of the Excited-State Reduction Potential Ered": As an approximation, the excited-state potentials of a catalyst are related to its ground state potentials $\left(\mathrm{E}_{1 / 2}\left(\mathrm{Cu}^{\mathrm{II}} / \mathrm{Cu}^{\mathrm{I}}\right)=-0.5 \mathrm{~V}\right.$, and the ground state potential was calculated from 
the peak potential DPV scanning) and its free energy (zero-zero excitation energy, $\mathrm{E}^{0-}$ ${ }^{0}=2.02 \mathrm{eV}$, the $\mathrm{E}^{0-0}$ of the $\mathrm{Cu}-\mathrm{TFT}$ was calculated by the solid-state $\mathrm{UV}$ and fluorescence spectra).

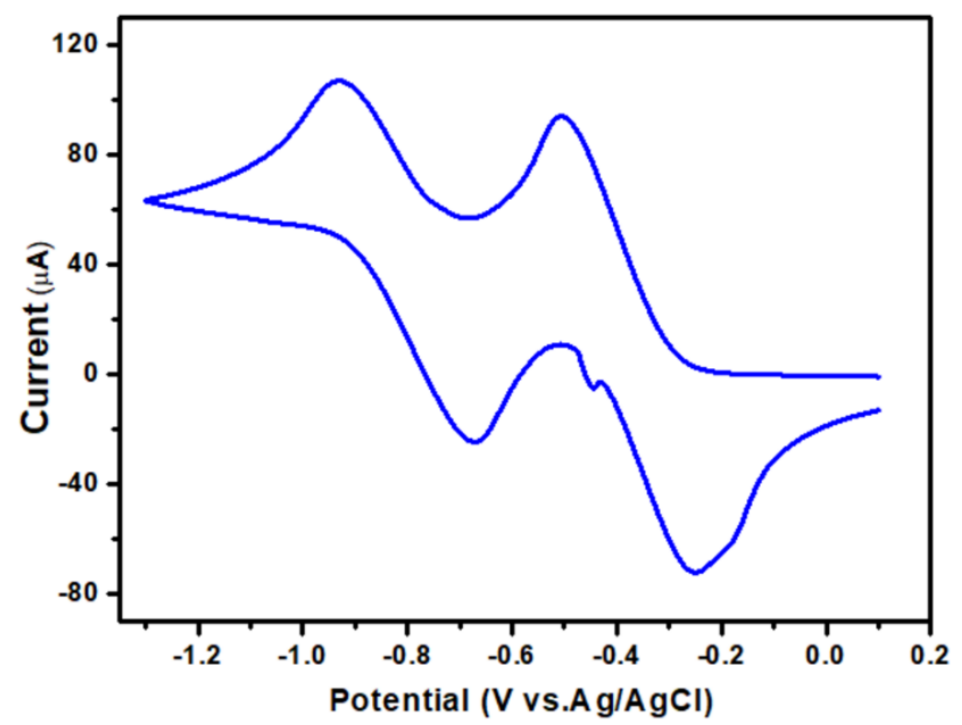

Figure S14. Cyclic voltammogram of $\mathbf{B Q}$ measured in acetonitrile, scan rate $0.1 \mathrm{~V} / \mathrm{s}$. working electrode: carbon-paste electrode; reference electrode: $\mathrm{Ag} / \mathrm{AgCl}$ electrode; counter electrode: a platinum-wire; electrolyte: $0.1 \mathrm{M} \mathrm{Bu}_{4} \mathrm{NPF}_{6}$.

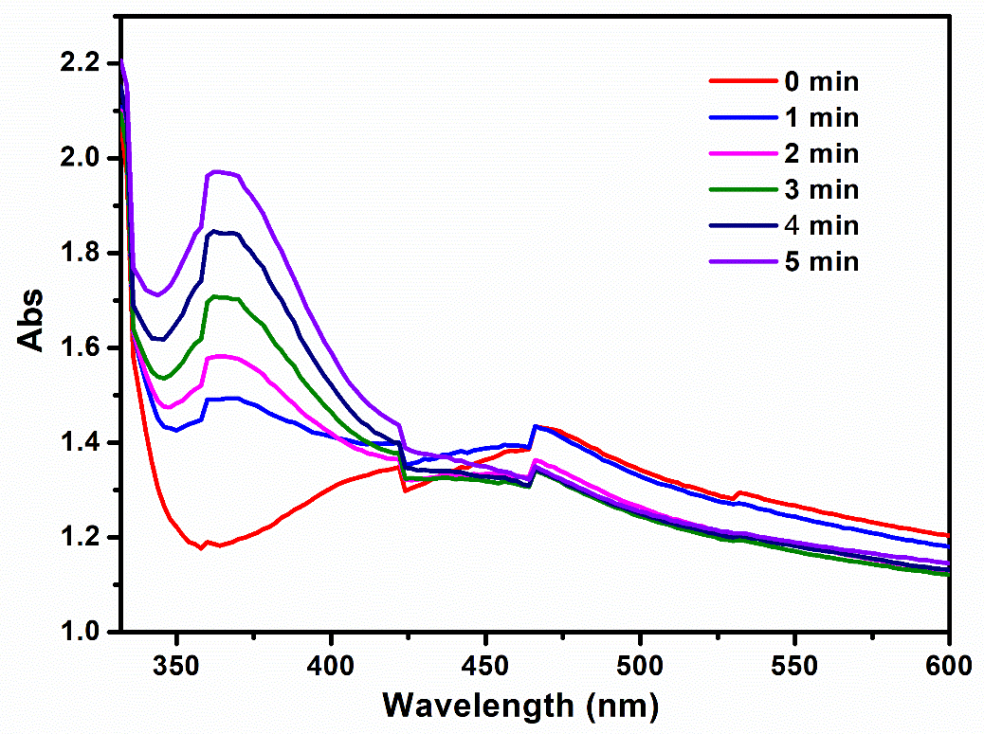

Figure S15. Time-dependent absorption spectra of $\mathrm{Cu}-$ TFT in the presence of TMB and phenylacetylene in air (the time corresponds to the irradiation time). 


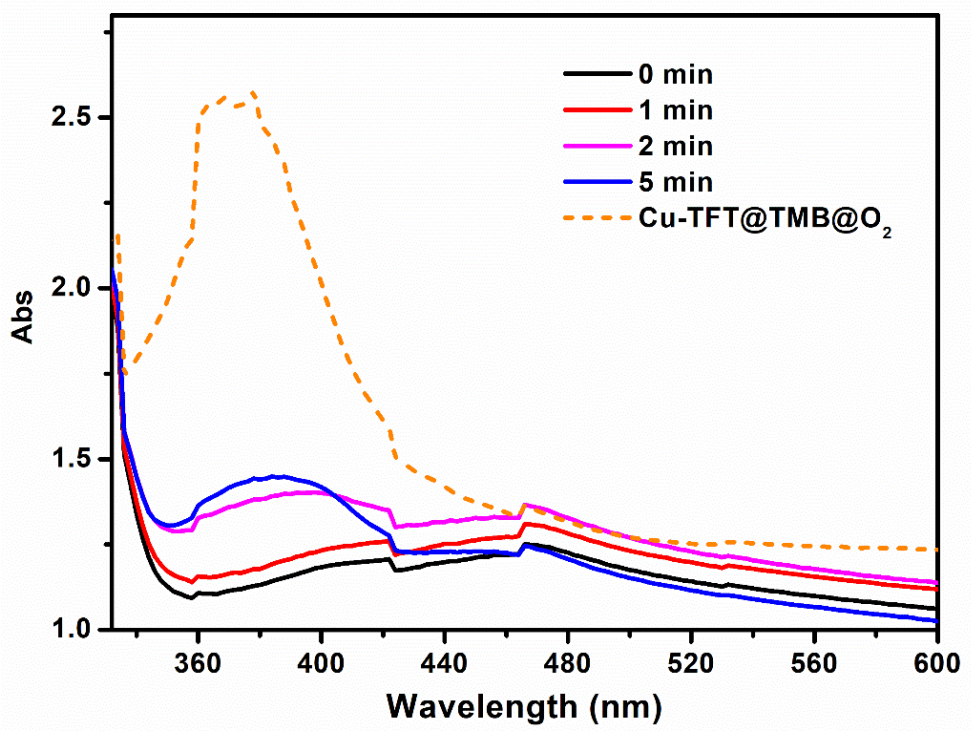

Figure S16. Time-dependent absorption spectra of $\mathrm{Cu}-\mathbf{T F T}$ in the presence of TMB and phenylacetylene in $\mathrm{N}_{2}$ (the time corresponds to the irradiation time), and the orange dotted line was the absorption spectra of $\mathrm{Cu}$-TFT in the presence of TMB and phenylacetylene in $\mathrm{O}_{2}$ after irradiation $10 \mathrm{~min}$.

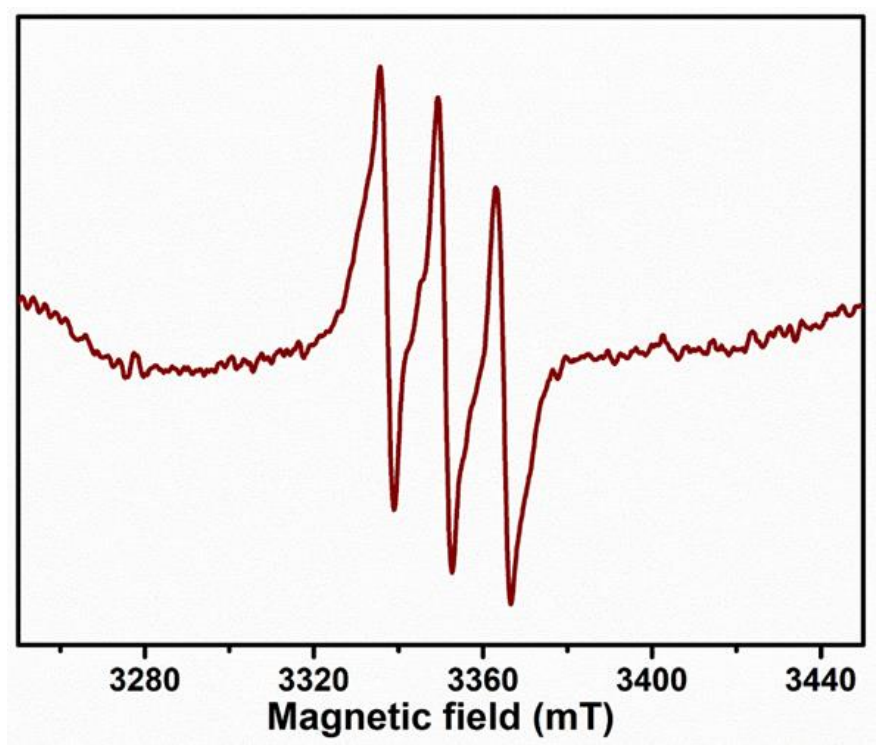

Figure S17. EPR spectra of the reaction mixture for the ${ }^{1} \mathrm{O}_{2}$ detection in the presence of 4-oxo-TMP. 


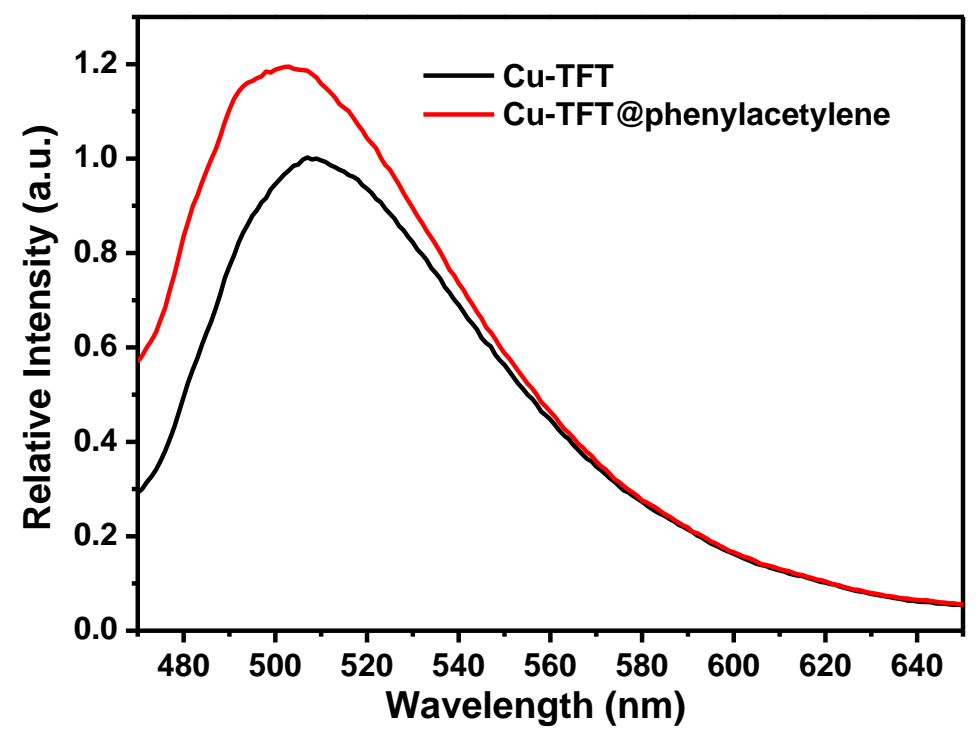

Figure S18. Emission spectra of $\mathrm{Cu}-$ TFT in $\mathrm{CH}_{3} \mathrm{CN}$ suspension upon addition of phenylacetylene, excitation at $450 \mathrm{~nm}$.

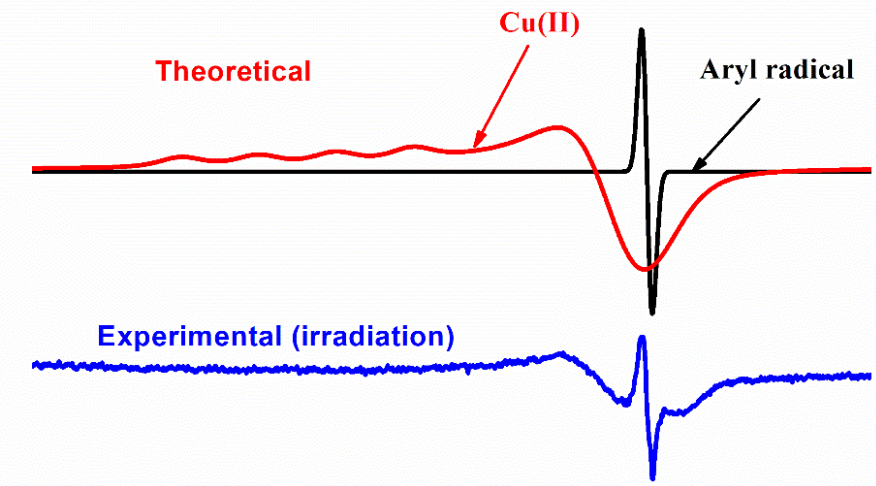

Experimental (dark)

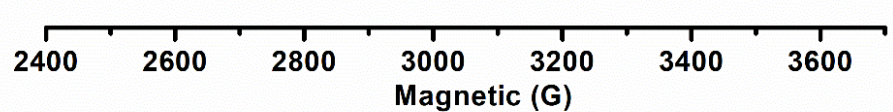

Figure S19. EPR of $\mathrm{Cu}-\mathrm{TFT} @ 3 \mathbf{3 a} @ \mathbf{4 a}$ with (blue line) or without (green line) light irradiation. 


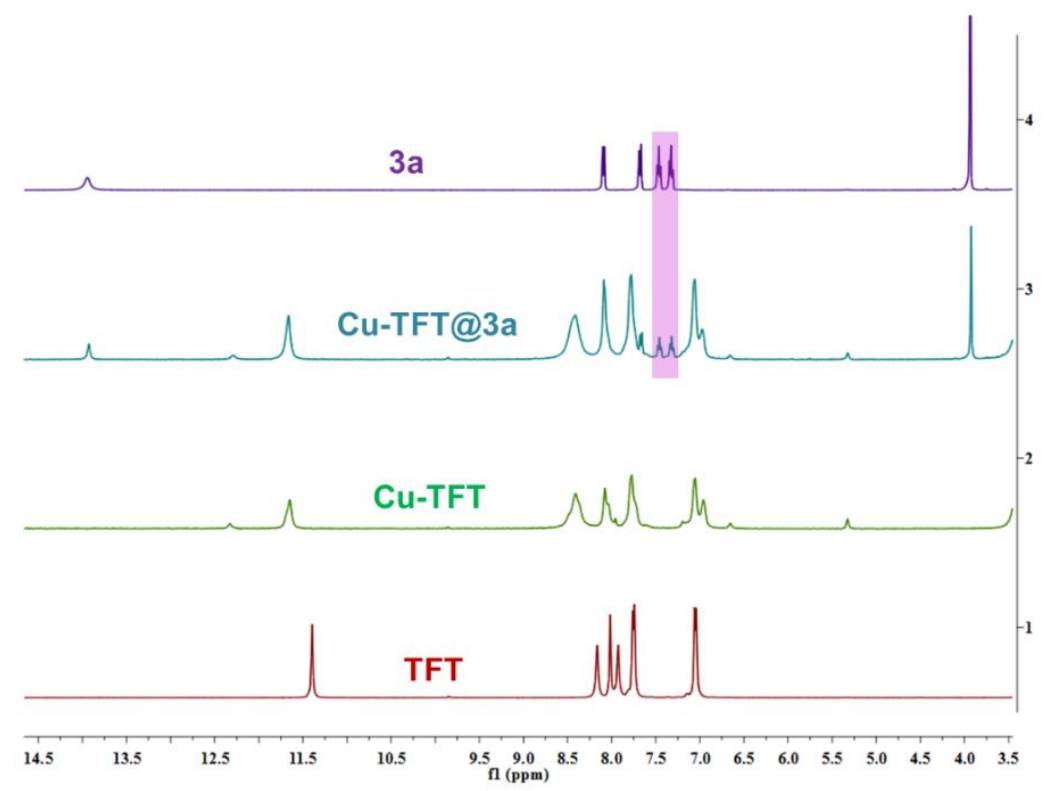

Figure S20. ${ }^{1} \mathrm{H}$ NMR spectra of the crystals of TFT, 3a, Cu-TFT and $\mathrm{Cu}-$ TFT @3a (digested in DMSO-d 6 ).

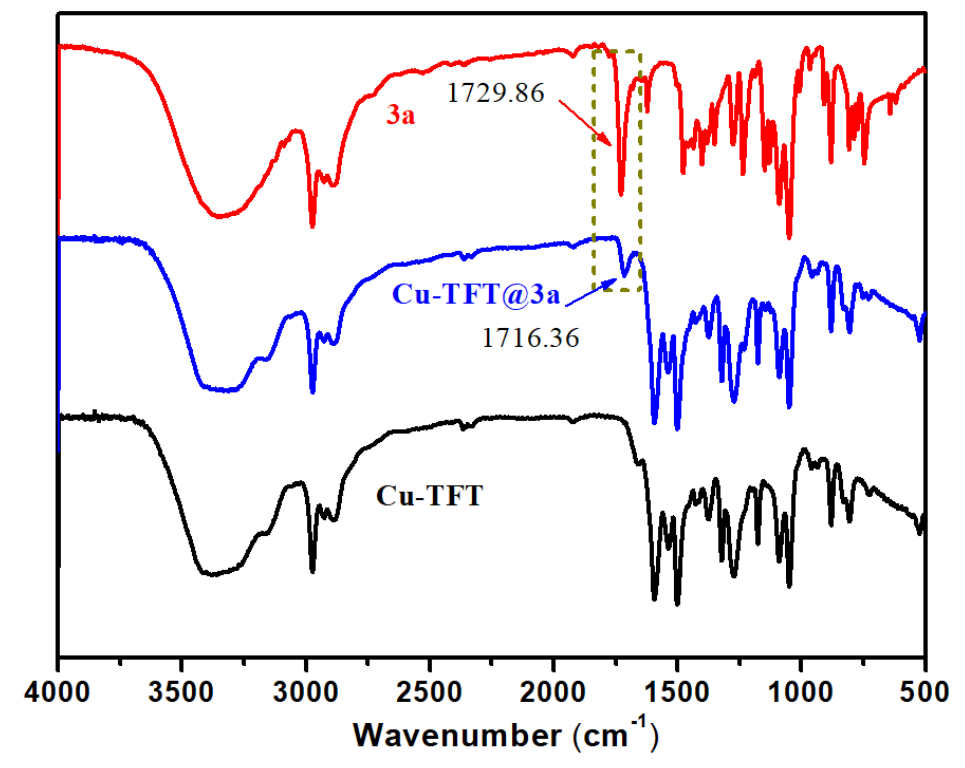

Figure S21. Comparison of the infrared (IR) spectra of $\mathrm{Cu}$-TFT (black line), 3a (red line) and Cu-TFT@3a (blue line). 


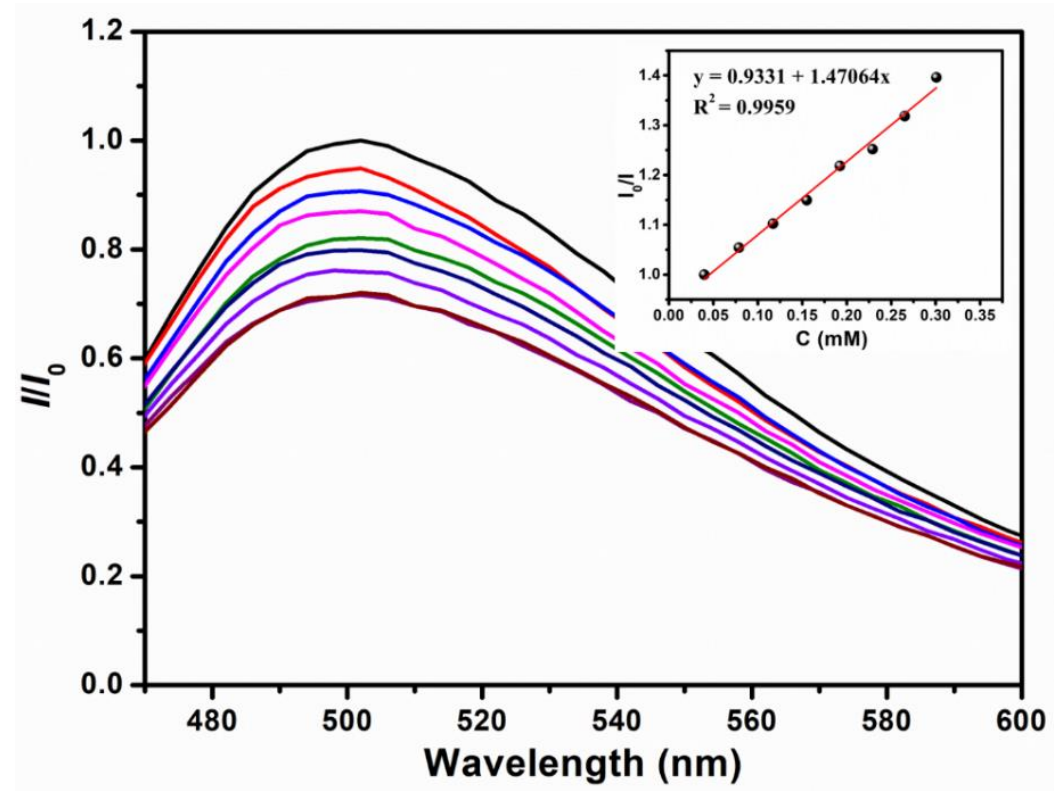

Figure S22. Fluorescence spectra of $\mathrm{Cu}-\mathbf{T F T} @ 3 \mathbf{3}$ suspension in acetonitrile upon the addition of thianthrenium salt $\mathbf{4 a}$.

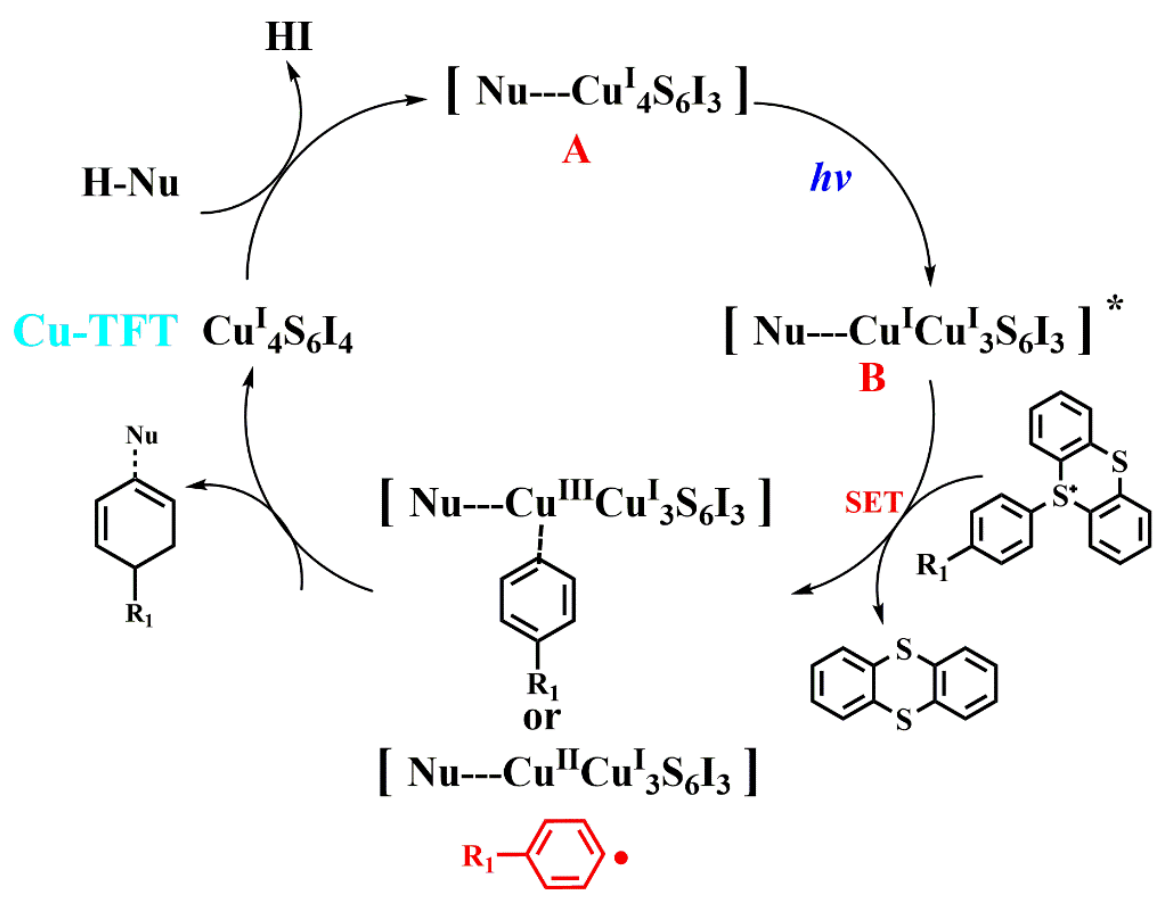

Figure S23. Schematic of the reaction mechanism. 


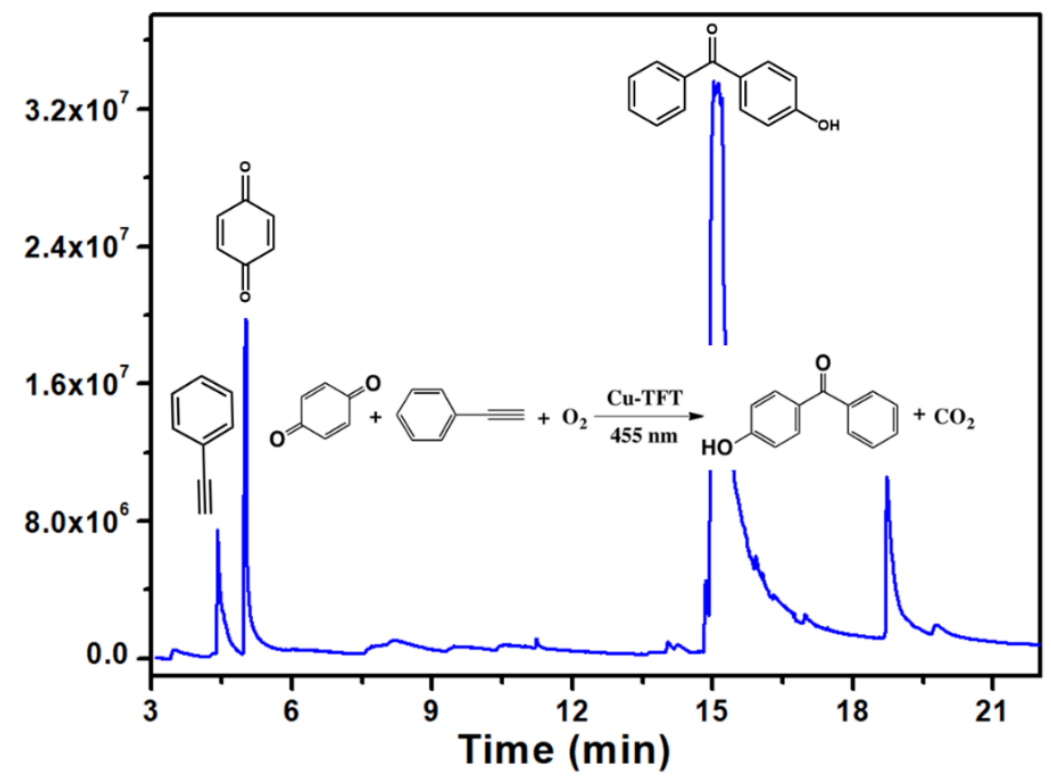

Figure S24. GC-MS spectrum of experiment mixture.

\section{Catalysis Details}

\section{Photoredox-catalyzed Aerobic Oxidative Coupling of Benzoquinone and Terminal} alkynes.

The terminal alkyne $(0.5 \mathrm{mmol}), \mathbf{B Q}(0.5 \mathrm{mmol}), \mathrm{Cu}-\mathbf{T F T}(8.0 \mathrm{mg})$ and ultra-dry acetonitrile were added to an oven-dried $15 \mathrm{~mL}$ quartz test tube which contained a stir bar. Rubber spacers were installed in the test tube, the joint was wrapped with sealing film, and freeze the test tube under liquid nitrogen, then was evacuated and backfilled with nitrogen ( 3 cycles). The resulting mixture was stirred and equipped with water bath and irradiated with a $455 \mathrm{~nm}$ LED lamp for $8 \mathrm{~h}$ under room temperature. The catalyst was seperated by centrifugation and filtration, then the solvent was removed under reduced pressure, and the residue was purified by chromatography using (hexane/ethyl acetate) as the solvent system. 


\section{C-N Cross-Coupling: Scope of Aryl Thianthreniums and N-Nucleophiles}

The nucleophile $(0.15 \mathrm{mmol})$, thianthrenium salt $(0.3 \mathrm{mmol})$, BTMG $(0.6 \mathrm{mmol})$, $\mathrm{Cu}$-TFT $(8.0 \mathrm{mg})$ and ultra-dry acetonitrile were added to an oven-dried $15 \mathrm{~mL}$ quartz test tube which contained a stir bar. Rubber spacers were installed in the test tube, the joint was wrapped with sealing film, and freeze the test tube under liquid nitrogen, then was evacuated and backfilled with nitrogen ( 3 cycles). The resulting mixture was stirred and equipped with water bath and irradiated with a $455 \mathrm{~nm}$ LED lamp for $6 \mathrm{~h}$ under room temperature. The catalyst was seperated by centrifugation and filtration, then the solvent was removed under reduced pressure, and the residue was purified by chromatography using (hexane/ $\mathrm{CH}_{2} \mathrm{Cl}_{2}$ ) as the solvent system.

Table S3. Optimization of the Reaction Conditions ${ }^{a, b}$

\begin{tabular}{cccccc}
\hline catalyst & base & solvent & light & Yield [\%] \\
\hline 1 & $\mathrm{Cu}-$ TFT & $\mathrm{BTMG}$ & $\mathrm{CH}_{3} \mathrm{CN}$ & $455 \mathrm{~nm}$ & 53 \\
2 & $\mathrm{Cu}-$ TFT & $\mathrm{DBU}$ & $\mathrm{CH}_{3} \mathrm{CN}$ & $455 \mathrm{~nm}$ & $\mathrm{nr}$ \\
3 & $\mathrm{Cu}-\mathbf{T F T}$ & $\mathrm{K}_{2} \mathrm{CO}_{3}$ & $\mathrm{CH}_{3} \mathrm{CN}$ & $455 \mathrm{~nm}$ & $\mathrm{nr}$ \\
4 & $\mathrm{Cu}-\mathbf{T F T}$ & $\mathrm{none}$ & $\mathrm{CH}_{3} \mathrm{CN}$ & $455 \mathrm{~nm}$ & 0 \\
5 & $\mathrm{Cu}-\mathbf{T F T}$ & $\mathrm{BTMG}$ & $\mathrm{CH}_{3} \mathrm{CN}$ & $395 \mathrm{~nm}$ & 49 \\
6 & $\mathrm{CuI}$ & $\mathrm{BTMG}$ & $\mathrm{CH}_{3} \mathrm{CN}$ & $455 \mathrm{~nm}$ & 12 \\
7 & TFT & $\mathrm{BTMG}$ & $\mathrm{CH}_{3} \mathrm{CN}$ & $455 \mathrm{~nm}$ & 0 \\
\hline
\end{tabular}

[a] Yield of separated product. [b] Standard conditions: nucleophile $(0.15 \mathrm{mmol})$, thianthrenium salts $(0.3 \mathrm{mmol})$, catalyst $(0.01 \mathrm{mmol})$, ultradry $\mathrm{CH}_{3} \mathrm{CN}(6 \mathrm{~mL}) ; 1,8$ Diazabicyclo[5.4.0]undec-7-ene (DBU). 
Photocatalytic products:<smiles>O=C(c1ccccc1)c1ccc(O)cc1</smiles>

(4-hydroxyphenyl) (phenyl)methanone (2a): Purified by chromatography (hexane / ethyl acetate). ${ }^{1} \mathrm{H}-\mathrm{NMR}(400 \mathrm{MHz}, \mathrm{DMSO}) \delta 10.48$ (s, 1H), $7.75-7.65$ (m, 4H), 7.63 $(\mathrm{d}, \mathrm{J}=7.3 \mathrm{~Hz}, 1 \mathrm{H}), 7.54(\mathrm{t}, \mathrm{J}=7.4 \mathrm{~Hz}, 2 \mathrm{H}), 6.93(\mathrm{~d}, \mathrm{~J}=8.7 \mathrm{~Hz}, 2 \mathrm{H}) .{ }^{13} \mathrm{C}$ NMR $(101$ MHz, DMSO) $\delta 194.77,162.48,138.57,132.99,132.25,129.60,128.81,128.36$, 115.72<smiles>Cc1ccc(C(=O)c2ccc(O)cc2)cc1</smiles>

(4-hydroxyphenyl)(p-tolyl)methanone (2b): Purified by chromatography (hexane / ethyl acetate). ${ }^{1} \mathrm{H}-\mathrm{NMR}\left(600 \mathrm{MHz}, \mathrm{CDCl}_{3}\right) \delta 7.76(\mathrm{~d}, \mathrm{~J}=8.1 \mathrm{~Hz}, 2 \mathrm{H}), 7.68(\mathrm{~d}, \mathrm{~J}=7.5$ $\mathrm{Hz}, 2 \mathrm{H}), 7.28(\mathrm{~d}, \mathrm{~J}=7.5 \mathrm{~Hz}, 2 \mathrm{H}), 6.92(\mathrm{~d}, \mathrm{~J}=8.0 \mathrm{~Hz}, 2 \mathrm{H}), 6.61(\mathrm{~d}, \mathrm{~J}=23.6 \mathrm{~Hz}, 1 \mathrm{H})$, $2.44(\mathrm{~s}, 3 \mathrm{H}) .{ }^{13} \mathrm{C}-\mathrm{NMR}\left(151 \mathrm{MHz}, \mathrm{CDCl}_{3}\right) \delta 196.07,160.09,142.89,135.35,132.87$, $130.24,130.11,128.95,115.20,21.64$<smiles>O=C(c1ccc(O)cc1)c1ccc(F)cc1</smiles>

(4-fluorophenyl)(4-hydroxyphenyl)methanone (2c): Purified by chromatography (hexane / ethyl acetate). ${ }^{1} \mathrm{H}-\mathrm{NMR}(600 \mathrm{MHz}, \mathrm{DMSO}) \delta 10.41(\mathrm{~s}, 1 \mathrm{H}), 7.76-7.65(\mathrm{~m}$, $2 \mathrm{H}), 7.61(\mathrm{~d}, \mathrm{~J}=8.3 \mathrm{~Hz}, 2 \mathrm{H}), 7.32(\mathrm{t}, \mathrm{J}=8.5 \mathrm{~Hz}, 2 \mathrm{H}), 6.86(\mathrm{~d}, \mathrm{~J}=8.2 \mathrm{~Hz}, 2 \mathrm{H}) .{ }^{13} \mathrm{C}-$ NMR (151 MHz, DMSO) $\delta$ 192.96, 164.98, 163.33, 162.01, 134.58, 134.56, 132.46, 
<smiles>O=C(c1ccc(O)cc1)c1ccc(Cl)cc1</smiles>

(4-chlorophenyl)(4-hydroxyphenyl)methanone (2d): Purified by chromatography (hexane / ethyl acetate). ${ }^{1} \mathrm{H}-\mathrm{NMR}(600 \mathrm{MHz}, \mathrm{DMSO}) \delta 10.50(\mathrm{~s}, 1 \mathrm{H}), 7.68$ (dd, J = 13.3, $8.4 \mathrm{~Hz}, 4 \mathrm{H}), 7.60(\mathrm{~d}, \mathrm{~J}=8.2 \mathrm{~Hz}, 2 \mathrm{H}), 6.91(\mathrm{~d}, \mathrm{~J}=8.4 \mathrm{~Hz}, 2 \mathrm{H}) .{ }^{13} \mathrm{C}-\mathrm{NMR}(151$ MHz, DMSO) $\delta 198.75,166.46,142.58,136.95,136.24,133.56,132.86,132.36$, 119.72 .<smiles>O=C(c1ccc(O)cc1)c1ccc(Br)cc1</smiles>

(4-bromophenyl)(4-hydroxyphenyl)methanone (2e): Purified by chromatography (hexane / ethyl acetate). ${ }^{1} \mathrm{H}-\mathrm{NMR}(600 \mathrm{MHz}, \mathrm{DMSO}) \delta 10.49(\mathrm{~s}, 1 \mathrm{H}), 7.75$ (d, J = 8.1 $\mathrm{Hz}, 2 \mathrm{H}), 7.66(\mathrm{~d}, \mathrm{~J}=8.3 \mathrm{~Hz}, 2 \mathrm{H}), 7.61(\mathrm{~d}, \mathrm{~J}=8.1 \mathrm{~Hz}, 2 \mathrm{H}), 6.90(\mathrm{~d}, \mathrm{~J}=8.2 \mathrm{~Hz}, 2 \mathrm{H})$. ${ }^{13} \mathrm{C}-\mathrm{NMR}$ (151 MHz, DMSO) $\delta$ 193.27, 162.18, 137.10, 132.52, 131.42, 131.15, 127.51, $125.63,115.32$<smiles>O=C(c1ccc(O)cc1)C1CCCCC1</smiles>

cyclohexyl(4-hydroxyphenyl)methanone (2f): Purified by chromatography (hexane / ethyl acetate). ${ }^{1} \mathrm{H}-\mathrm{NMR}(600 \mathrm{MHz}, \mathrm{DMSO}) \delta 10.31(\mathrm{~s}, 1 \mathrm{H}), 7.84(\mathrm{~d}, \mathrm{~J}=8.2 \mathrm{~Hz}, 2 \mathrm{H})$, $6.85(\mathrm{~d}, \mathrm{~J}=8.2 \mathrm{~Hz}, 2 \mathrm{H}), 1.74(\mathrm{~d}, \mathrm{~J}=10.6 \mathrm{~Hz}, 4 \mathrm{H}), 1.67(\mathrm{~d}, \mathrm{~J}=13.0 \mathrm{~Hz}, 2 \mathrm{H}), 1.42-$ 1.29 (m, 4H). ${ }^{13} \mathrm{C}-\mathrm{NMR}$ (151 MHz, DMSO) $\delta$ 201.72, 162.31, 131.08, 127.69, 115.74, 
<smiles>O=C(c1ccc(O)cc1)c1cccs1</smiles>

(4-hydroxyphenyl)(thiophen-2-yl)methanone (2g): Purified by chromatography (hexane / ethyl acetate). ${ }^{1} \mathrm{H}-\mathrm{NMR}(600 \mathrm{MHz}, \mathrm{DMSO}) \delta 10.41$ (s, 1H), $8.04(\mathrm{~d}, \mathrm{~J}=4.8$ $\mathrm{Hz}, 1 \mathrm{H}), 7.78(\mathrm{~d}, \mathrm{~J}=8.3 \mathrm{~Hz}, 2 \mathrm{H}), 7.72(\mathrm{~d}, \mathrm{~J}=3.3 \mathrm{~Hz}, 1 \mathrm{H}), 7.27(\mathrm{t}, \mathrm{J}=4.2 \mathrm{~Hz}, 1 \mathrm{H}), 6.92$ $(\mathrm{d}, \mathrm{J}=8.3 \mathrm{~Hz}, 2 \mathrm{H}) .{ }^{13} \mathrm{C}-\mathrm{NMR}(151 \mathrm{MHz}, \mathrm{DMSO}) \delta 186.13,162.29,143.66,134.84$, 134.71, 132.12, 128.97, 128.84, 115.81.<smiles>CC(=O)c1nn(-c2ccc(Oc3ccccc3)cc2)c2ccccc12</smiles>

(4-hydroxyphenyl)(thiophen-2-yl)methanone (5a): Purified by chromatography (hexane $\left./ \mathrm{CH}_{2} \mathrm{Cl}_{2}\right) .{ }^{1} \mathrm{H}-\mathrm{NMR}\left(600 \mathrm{MHz}, \mathrm{CDCl}_{3}\right) \delta 8.32(\mathrm{~d}, \mathrm{~J}=8.2 \mathrm{~Hz}, 1 \mathrm{H}), 7.68(\mathrm{~d}, \mathrm{~J}=$ $8.7 \mathrm{~Hz}, 3 \mathrm{H}), 7.48(\mathrm{t}, \mathrm{J}=7.7 \mathrm{~Hz}, 1 \mathrm{H}), 7.39(\mathrm{t}, \mathrm{J}=7.7 \mathrm{~Hz}, 3 \mathrm{H}), 7.17(\mathrm{t}, \mathrm{J}=7.8 \mathrm{~Hz}, 3 \mathrm{H})$, $7.08(\mathrm{~d}, \mathrm{~J}=7.8 \mathrm{~Hz}, 2 \mathrm{H}), 4.07(\mathrm{~s}, 3 \mathrm{H}) .{ }^{13} \mathrm{C}-\mathrm{NMR}\left(151 \mathrm{MHz}, \mathrm{CDCl}_{3}\right) \delta 163.05,157.18$, $156.65,140.36,136.51,134.24,129.97,127.66,125.58,124.33,123.92,123.74$, 122.40, 119.40, 119.24, 110.75, 52.18 .<smiles>CC(=O)c1nn(-c2ccc(Oc3ccccc3)cc2)c2ccccc12</smiles>

(4-hydroxyphenyl)(thiophen-2-yl)methanone (5b): Purified by chromatography 
(hexane / $\left.\mathrm{CH}_{2} \mathrm{Cl}_{2}\right) .{ }^{1} \mathrm{H}-\mathrm{NMR}\left(600 \mathrm{MHz}, \mathrm{CDCl}_{3}\right) \delta 8.46(\mathrm{~d}, \mathrm{~J}=8.1 \mathrm{~Hz}, 1 \mathrm{H}), 7.69(\mathrm{dd}, \mathrm{J}$ $=15.4,8.6 \mathrm{~Hz}, 3 \mathrm{H}), 7.47(\mathrm{t}, \mathrm{J}=7.5 \mathrm{~Hz}, 1 \mathrm{H}), 7.39(\mathrm{q}, \mathrm{J}=8.1 \mathrm{~Hz}, 3 \mathrm{H}), 7.22-7.16(\mathrm{~m}$, 3H), $7.10(\mathrm{t}, \mathrm{J}=9.4 \mathrm{~Hz}, 2 \mathrm{H}), 2.78(\mathrm{~s}, 3 \mathrm{H}) .{ }^{13} \mathrm{C}-\mathrm{NMR}\left(151 \mathrm{MHz}, \mathrm{CDCl}_{3}\right) \delta 195.09$, $157.15,156.58,143.77,140.50,134.44,130.00,127.65,125.20,124.16,124.00$, $123.37,123.24,119.43,119.34,110.47,26.96$.

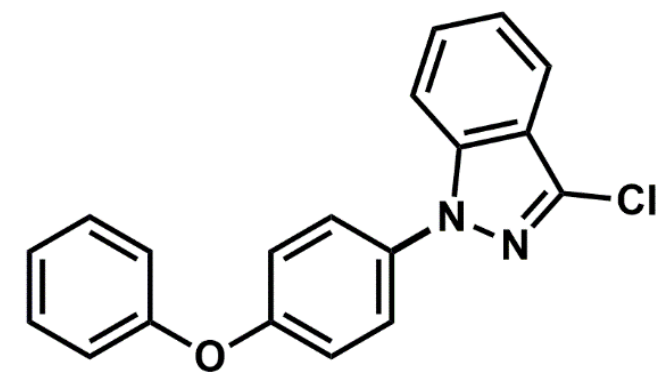

(4-hydroxyphenyl)(thiophen-2-yl)methanone (5c): Purified by chromatography (hexane $\left./ \mathrm{CH}_{2} \mathrm{Cl}_{2}\right) .{ }^{1} \mathrm{H}-\mathrm{NMR}\left(400 \mathrm{MHz}, \mathrm{CDCl}_{3}\right) \delta 8.28(\mathrm{~d}, \mathrm{~J}=5.2 \mathrm{~Hz}, 1 \mathrm{H}), 7.70-7.63$ $(\mathrm{m}, 2 \mathrm{H}), 7.53(\mathrm{~d}, \mathrm{~J}=3.6 \mathrm{~Hz}, 1 \mathrm{H}), 7.42-7.36(\mathrm{~m}, 2 \mathrm{H}), 7.23-7.14(\mathrm{~m}, 4 \mathrm{H}), 7.13-7.09$ $(\mathrm{m}, 2 \mathrm{H}), 6.77(\mathrm{~d}, \mathrm{~J}=3.6 \mathrm{~Hz}, 1 \mathrm{H}) . \delta 8.28(\mathrm{~d}, 1 \mathrm{H}), 7.67(\mathrm{~m}, 2 \mathrm{H}), 7.53(\mathrm{t}, 1 \mathrm{H}), 7.40(\mathrm{~m}$, 2H), $7.18(\mathrm{~m}, 4 \mathrm{H}), 7.11(\mathrm{~m}, 2 \mathrm{H}), 6.77(\mathrm{~d}, 1 \mathrm{H}) .{ }^{13} \mathrm{C}-\mathrm{NMR}\left(101 \mathrm{MHz}, \mathrm{CDCl}_{3}\right) \delta 156.88$, $156.31,140.09,135.70,134.74,129.94,128.36,124.43,123.76,122.24,122.13$, $120.09,119.55,119.13,110.58$.<smiles>N#Cc1nn(-c2ccc(Oc3ccccc3)cc2)c2ccccc12</smiles>

(4-hydroxyphenyl)(thiophen-2-yl)methanone (5d): Purified by chromatography (hexane $\left./ \mathrm{CH}_{2} \mathrm{Cl}_{2}\right) .{ }^{1} \mathrm{H}-\mathrm{NMR}\left(600 \mathrm{MHz}, \mathrm{CDCl}_{3}\right) \delta 7.93(\mathrm{~d}, \mathrm{~J}=8.2 \mathrm{~Hz}, 1 \mathrm{H}), 7.74(\mathrm{~d}, \mathrm{~J}=$ 8.6 Hz, 1H), $7.65(\mathrm{~d}, \mathrm{~J}=8.8 \mathrm{~Hz}, 2 \mathrm{H}), 7.57-7.53(\mathrm{~m}, 1 \mathrm{H}), 7.45-7.39(\mathrm{~m}, 4 \mathrm{H}), 7.19$ 
$(\mathrm{dd}, \mathrm{J}=7.8,5.9 \mathrm{~Hz}, 3 \mathrm{H}), 7.11(\mathrm{~d}, \mathrm{~J}=8.2 \mathrm{~Hz}, 2 \mathrm{H}) .{ }^{13} \mathrm{C}-\mathrm{NMR}\left(151 \mathrm{MHz}, \mathrm{CDCl}_{3}\right) \delta$ $157.71,156.31,139.20,133.65,130.05,128.57,125.95,125.17,124.20,119.91$, $119.53,119.29,113.38,111.33$.<smiles>Clc1ccnc2c1cnn2-c1ccc(Oc2ccccc2)cc1</smiles>

(4-hydroxyphenyl)(thiophen-2-yl)methanone (5e): Purified by chromatography (hexane $\left./ \mathrm{CH}_{2} \mathrm{Cl}_{2}\right) .{ }^{1} \mathrm{H}-\mathrm{NMR}\left(400 \mathrm{MHz}, \mathrm{CDCl}_{3}\right) \delta 8.28(\mathrm{~d}, \mathrm{~J}=5.2 \mathrm{~Hz}, 1 \mathrm{H}), 7.69-7.64$ (m, 2H), $7.53(\mathrm{~d}, \mathrm{~J}=3.6 \mathrm{~Hz}, 1 \mathrm{H}), 7.42-7.36(\mathrm{~m}, 2 \mathrm{H}), 7.21-7.14(\mathrm{~m}, 4 \mathrm{H}), 7.13-7.10$ $(\mathrm{m}, 2 \mathrm{H}), 6.77(\mathrm{~d}, \mathrm{~J}=3.6 \mathrm{~Hz}, 1 \mathrm{H}) .{ }^{13} \mathrm{C}-\mathrm{NMR}\left(101 \mathrm{MHz}, \mathrm{CDCl}_{3}\right) \delta 156.88,156.31$, $140.09,135.70,134.74,129.94,128.36,124.43,123.76,122.24,122.13,120.09$, $119.55,119.13,110.58$.

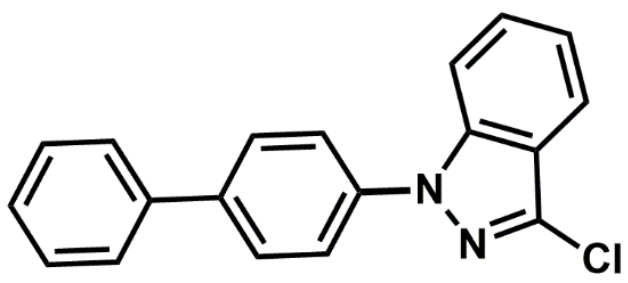

(4-hydroxyphenyl)(thiophen-2-yl)methanone (5f): Purified by chromatography (hexane $\left./ \mathrm{CH}_{2} \mathrm{Cl}_{2}\right) .{ }^{1} \mathrm{H}-\mathrm{NMR}\left(500 \mathrm{MHz}, \mathrm{CDCl}_{3}\right) \delta 7.80-7.73(\mathrm{~m}, 6 \mathrm{H}), 7.64(\mathrm{~d}, \mathrm{~J}=7.4$ $\mathrm{Hz}, 2 \mathrm{H}), 7.54-7.44(\mathrm{~m}, 3 \mathrm{H}), 7.38(\mathrm{t}, \mathrm{J}=7.4 \mathrm{~Hz}, 1 \mathrm{H}), 7.30(\mathrm{t}, \mathrm{J}=7.6 \mathrm{~Hz}, 1 \mathrm{H}) .{ }^{13} \mathrm{C}$ NMR $\left(151 \mathrm{MHz}, \mathrm{CDCl}_{3}\right) \delta 140.09,139.93,139.84,138.74,136.12,128.93,128.45$, $128.15,127.62,127.07,124.11,122.78,122.51,122.26,120.16,110.84$. 
<smiles>C=CCc1ccc(OC)c(-n2nc(Cl)c3ccccc32)c1</smiles>

(4-hydroxyphenyl)(thiophen-2-yl)methanone (5g): Purified by chromatography (hexane $\left./ \mathrm{CH}_{2} \mathrm{Cl}_{2}\right) .{ }^{1} \mathrm{H}-\mathrm{NMR}\left(600 \mathrm{MHz}, \mathrm{CDCl}_{3}\right) \delta 7.73(\mathrm{~d}, \mathrm{~J}=8.1 \mathrm{~Hz}, 1 \mathrm{H}), 7.40(\mathrm{t}, \mathrm{J}=$ $7.7 \mathrm{~Hz}, 1 \mathrm{H}), 7.30(\mathrm{~s}, 1 \mathrm{H}), 7.24(\mathrm{~d}, \mathrm{~J}=7.6 \mathrm{~Hz}, 2 \mathrm{H}), 7.21(\mathrm{~d}, \mathrm{~J}=8.5 \mathrm{~Hz}, 1 \mathrm{H}), 7.03(\mathrm{~d}, \mathrm{~J}$ $=8.4 \mathrm{~Hz}, 1 \mathrm{H}), 6.01-5.91(\mathrm{~m}, 1 \mathrm{H}), 5.09(\mathrm{t}, \mathrm{J}=12.4 \mathrm{~Hz}, 2 \mathrm{H}), 3.77(\mathrm{~s}, 3 \mathrm{H}), 3.39(\mathrm{~d}, \mathrm{~J}=$ $6.6 \mathrm{~Hz}, 2 \mathrm{H}) .{ }^{13} \mathrm{C}-\mathrm{NMR}\left(151 \mathrm{MHz}, \mathrm{CDCl}_{3}\right) \delta 152.35,141.75,137.02,135.27,132.93$, $129.76,128.62,127.61,127.55,121.56,121.45,119.52,116.20,112.32,111.61,55.90$ 39.08 .<smiles>Clc1nn(-c2ccc(Oc3ccc(Br)cc3)cc2)c2ccccc12</smiles>

(4-hydroxyphenyl)(thiophen-2-yl)methanone (5h): Purified by chromatography (hexane $\left./ \mathrm{CH}_{2} \mathrm{Cl}_{2}\right) .{ }^{1} \mathrm{H}-\mathrm{NMR}\left(400 \mathrm{MHz}, \mathrm{CDCl}_{3}\right) \delta 7.76(\mathrm{~d}, \mathrm{~J}=8.2 \mathrm{~Hz}, 1 \mathrm{H}), 7.69-7.62$ (m, 3H), $7.48(\mathrm{t}, \mathrm{J}=7.9 \mathrm{~Hz}, 3 \mathrm{H}), 7.32-7.27(\mathrm{~m}, 1 \mathrm{H}), 7.18-7.12(\mathrm{~m}, 2 \mathrm{H}), 6.99-6.90$ (m, 2H). ${ }^{13} \mathrm{C}-\mathrm{NMR}\left(101 \mathrm{MHz}, \mathrm{CDCl}_{3}\right) \delta 140.10,139.95,139.85,138.76,136.14$, $128.94,128.47,128.16,127.64,127.09,122.80,122.53,122.28,120.17,110.86$. 

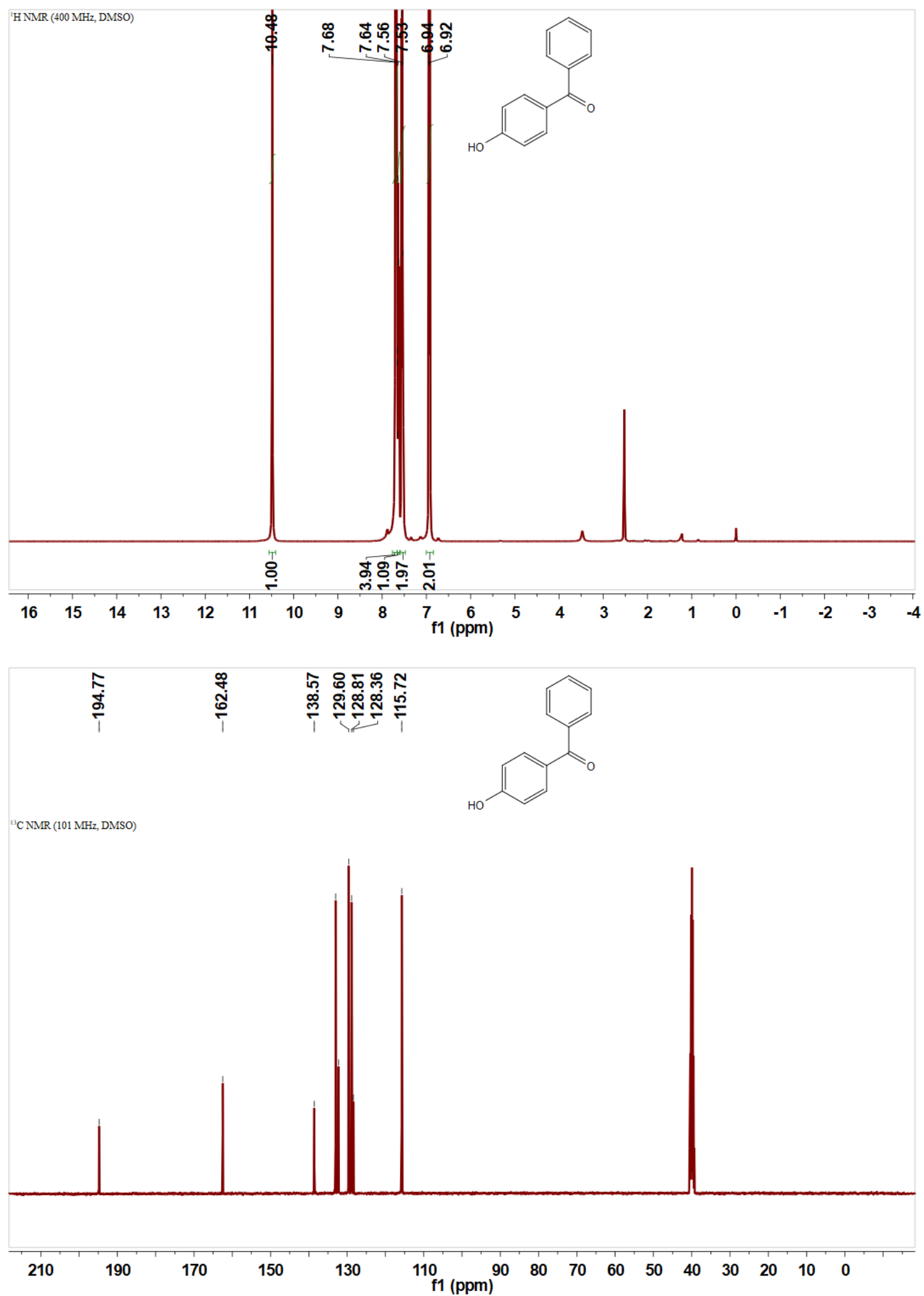

Figure S25. NMR spectra of $2 \mathbf{a}$. 

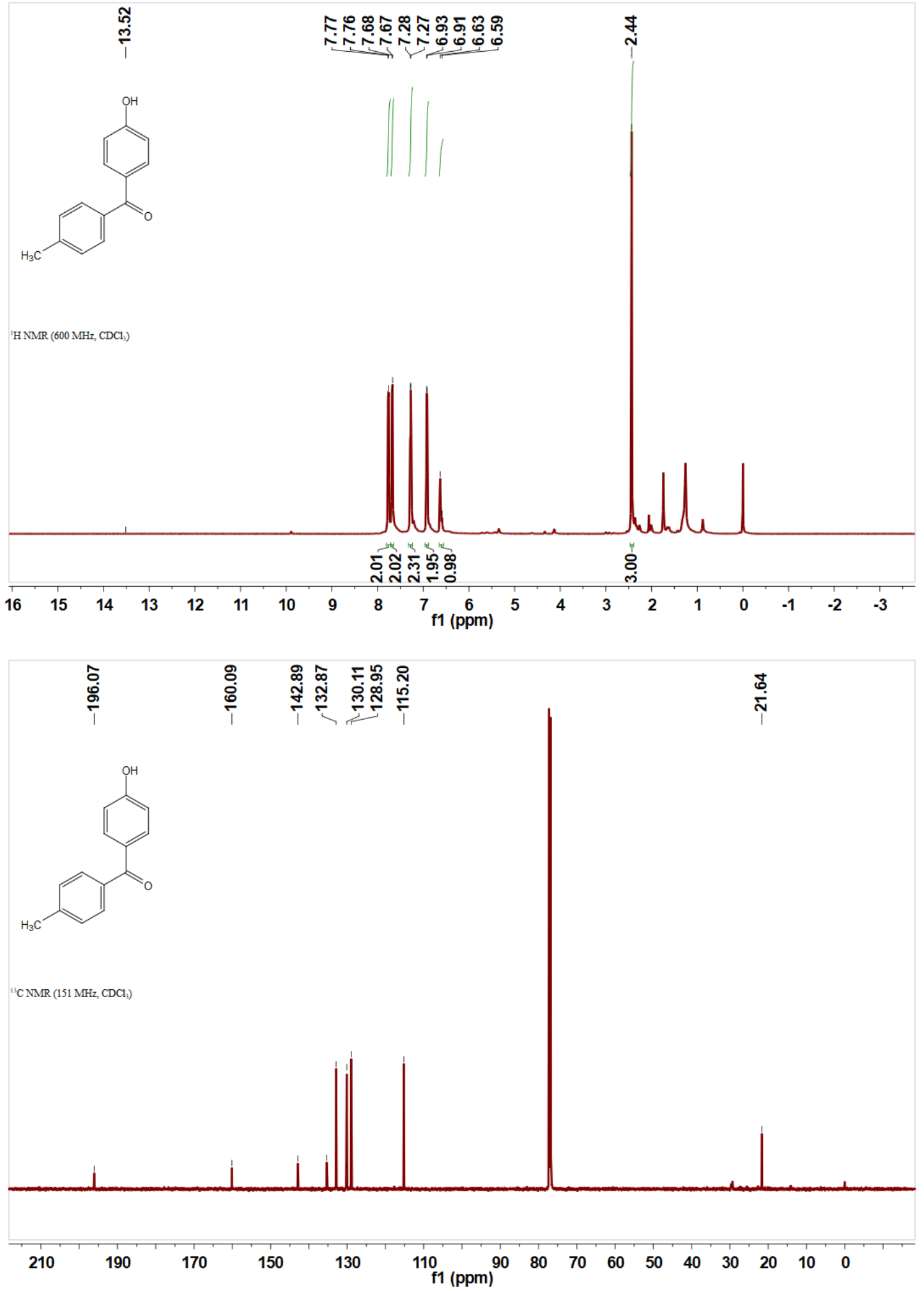

Figure S26. NMR spectra of $\mathbf{2 b}$. 

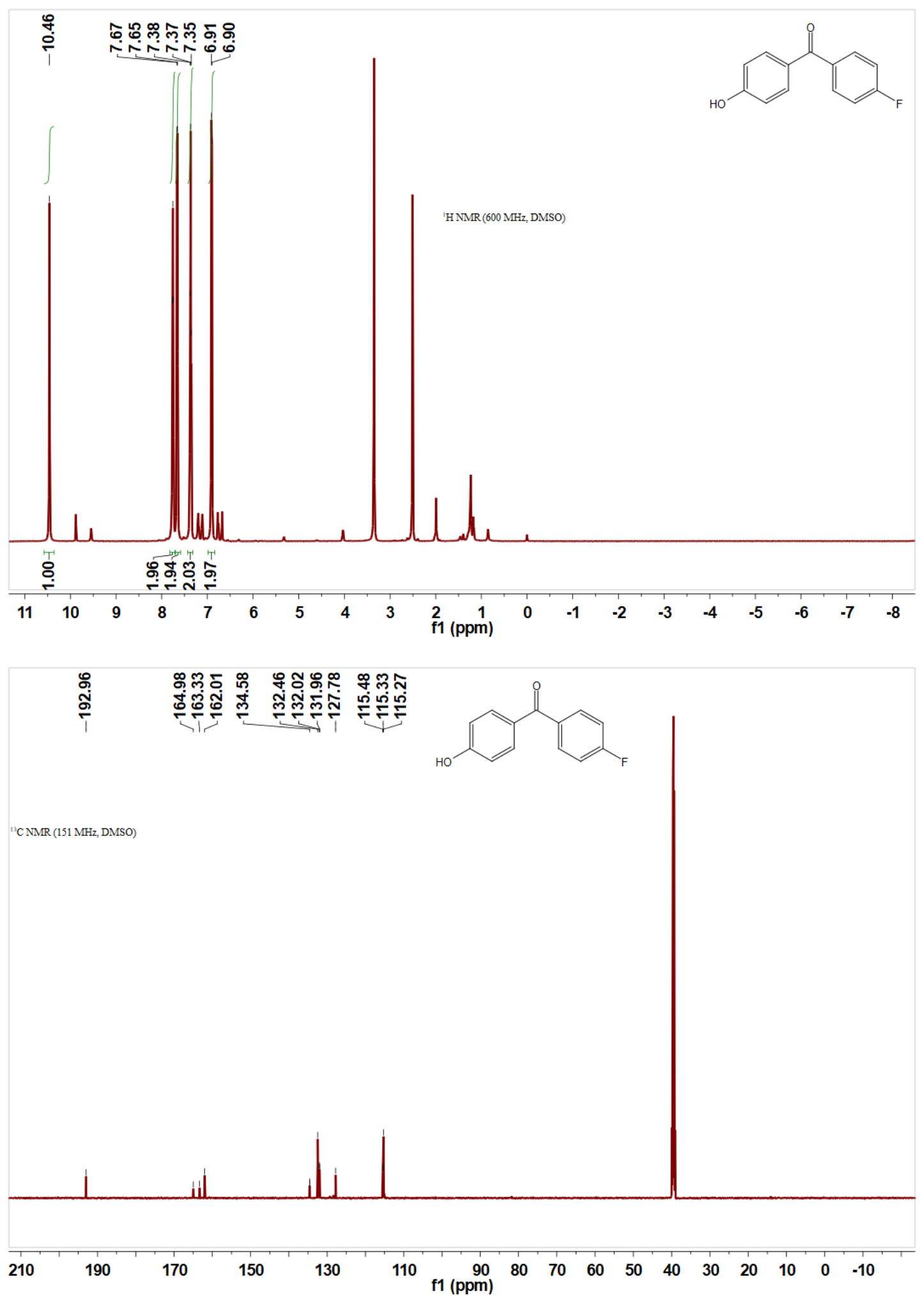

Figure S27. NMR spectra of 2c. 

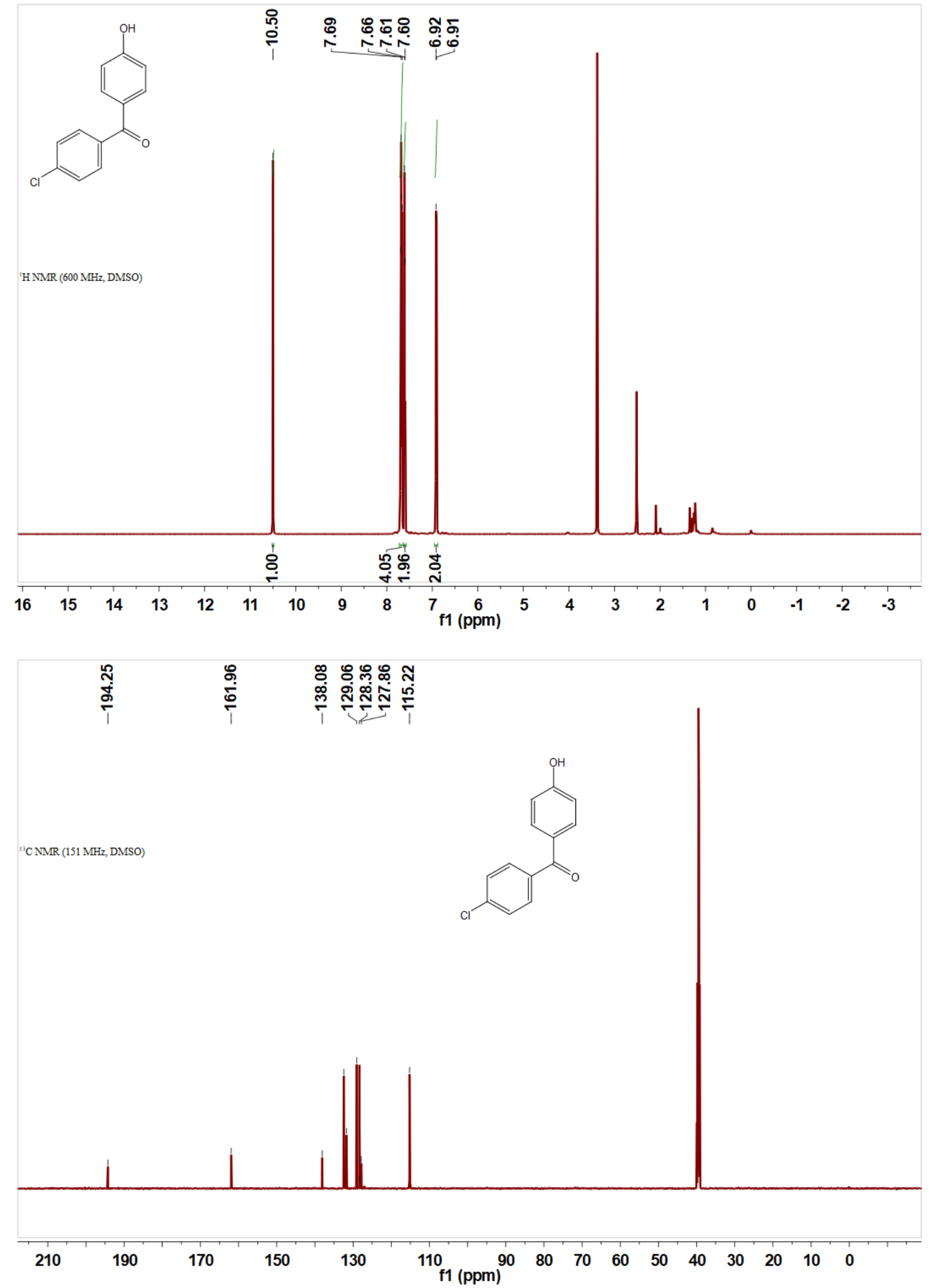

Figure S28. NMR spectra of 2d. 

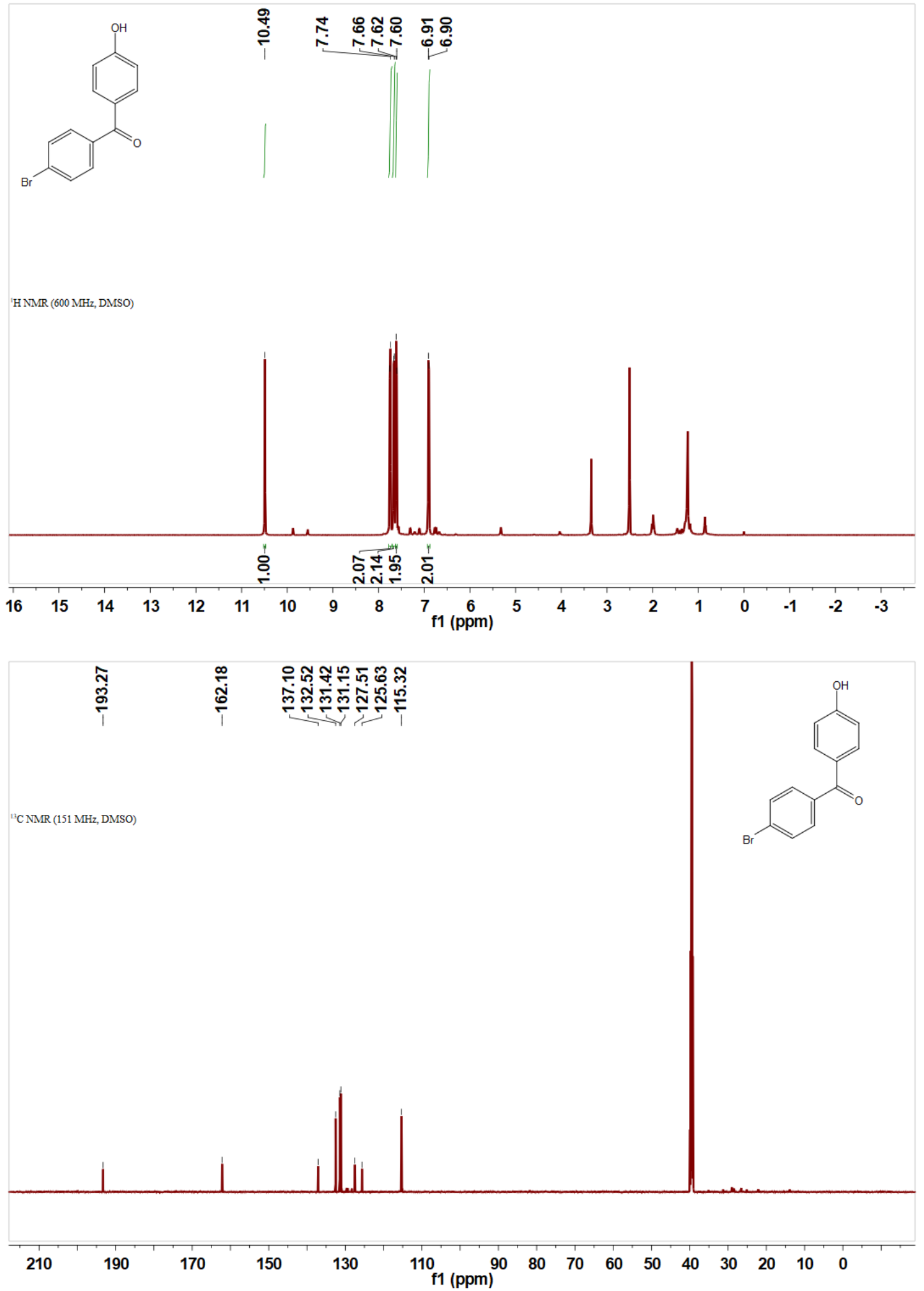

Figure S29. NMR spectra of 2e. 

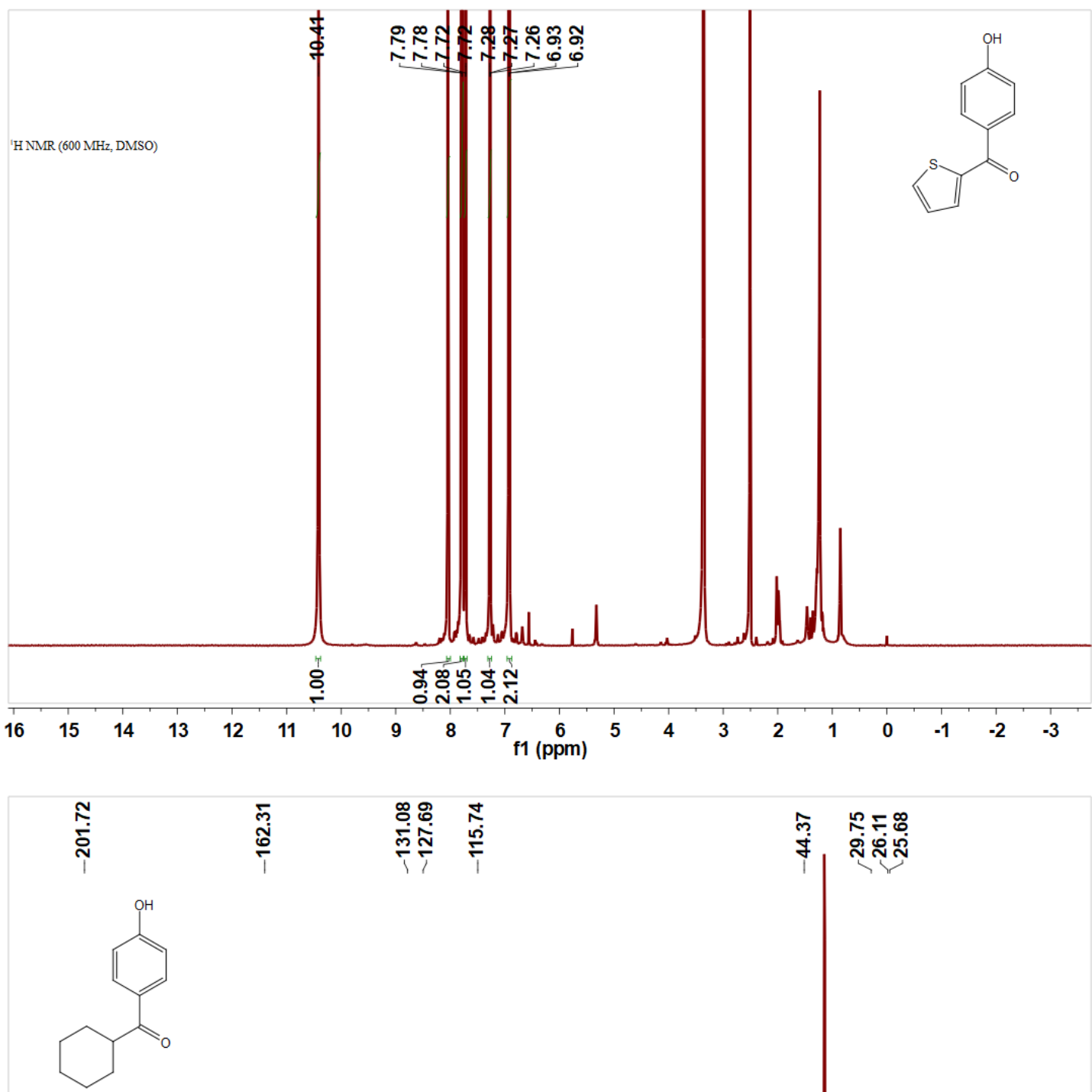

ஸ্লু

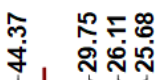

${ }^{13} \mathrm{C}$ NMR (151 MHz, DMSO)

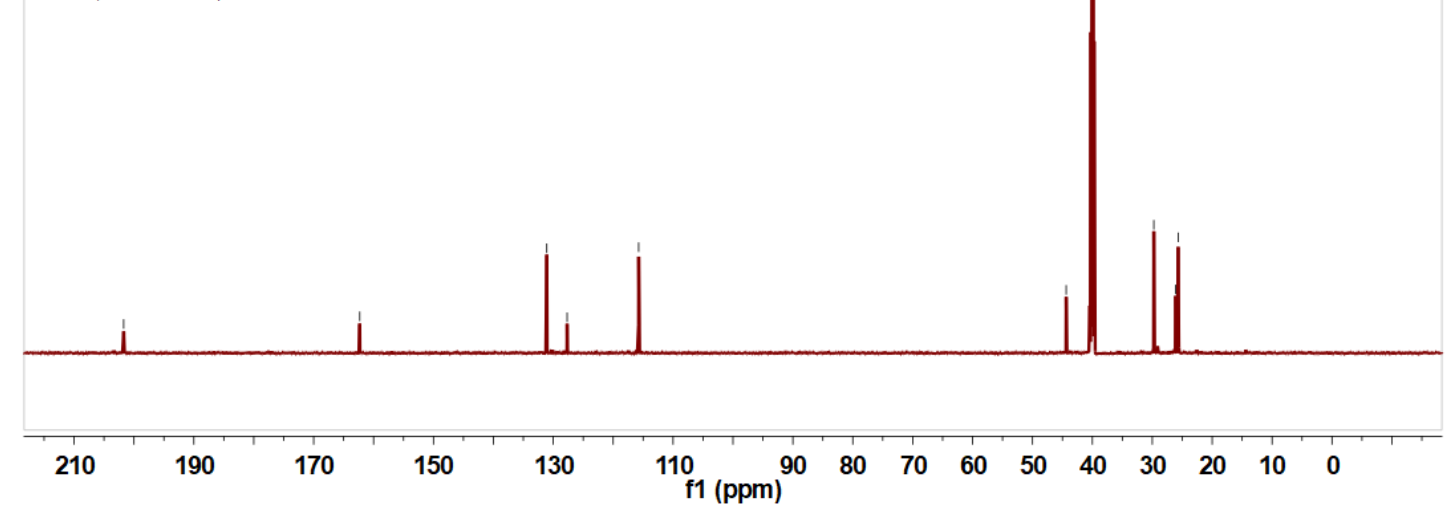

Figure S30. NMR spectra of $2 \mathbf{f}$. 

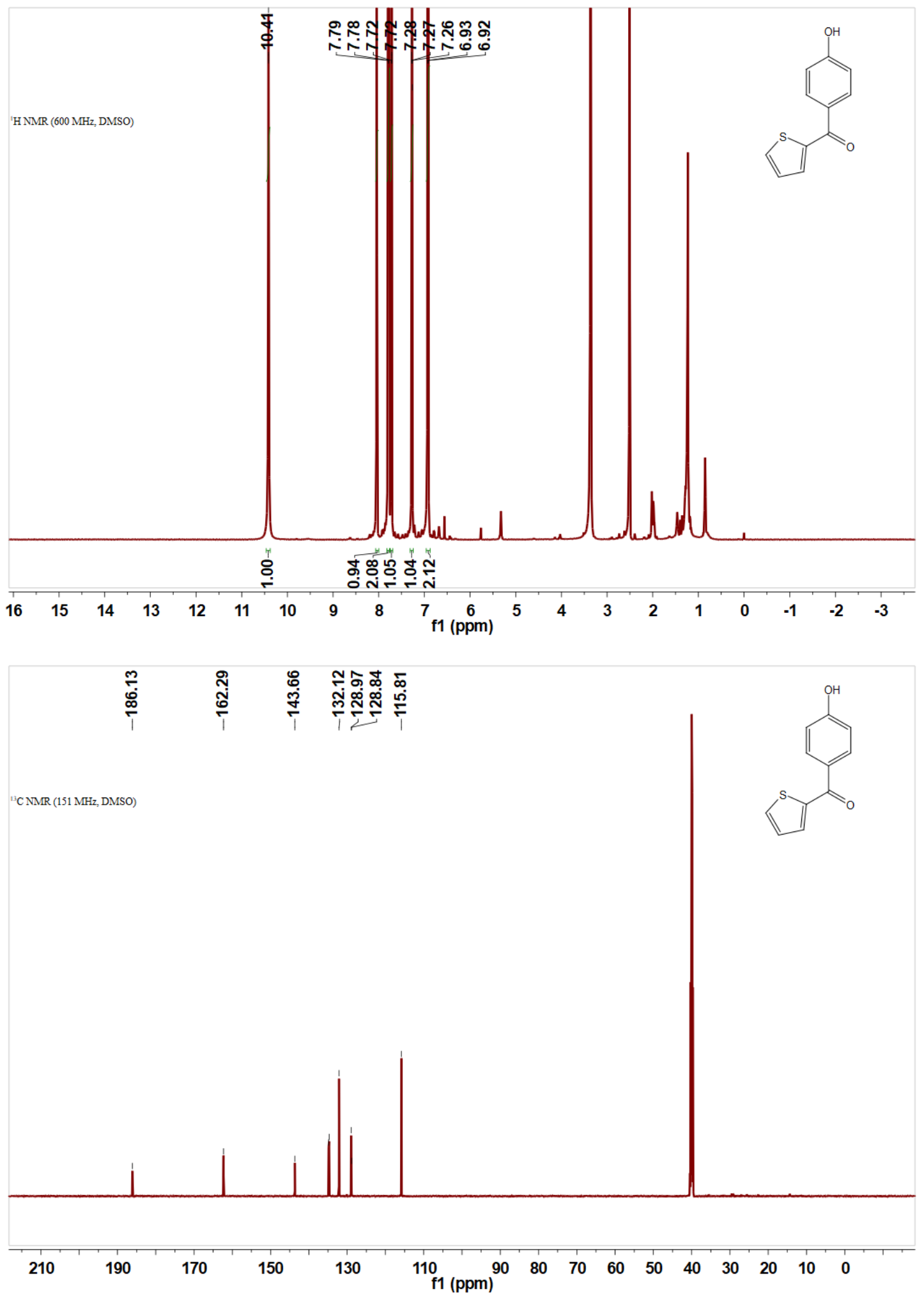

Figure S31. NMR spectra of $\mathbf{2 g}$. 

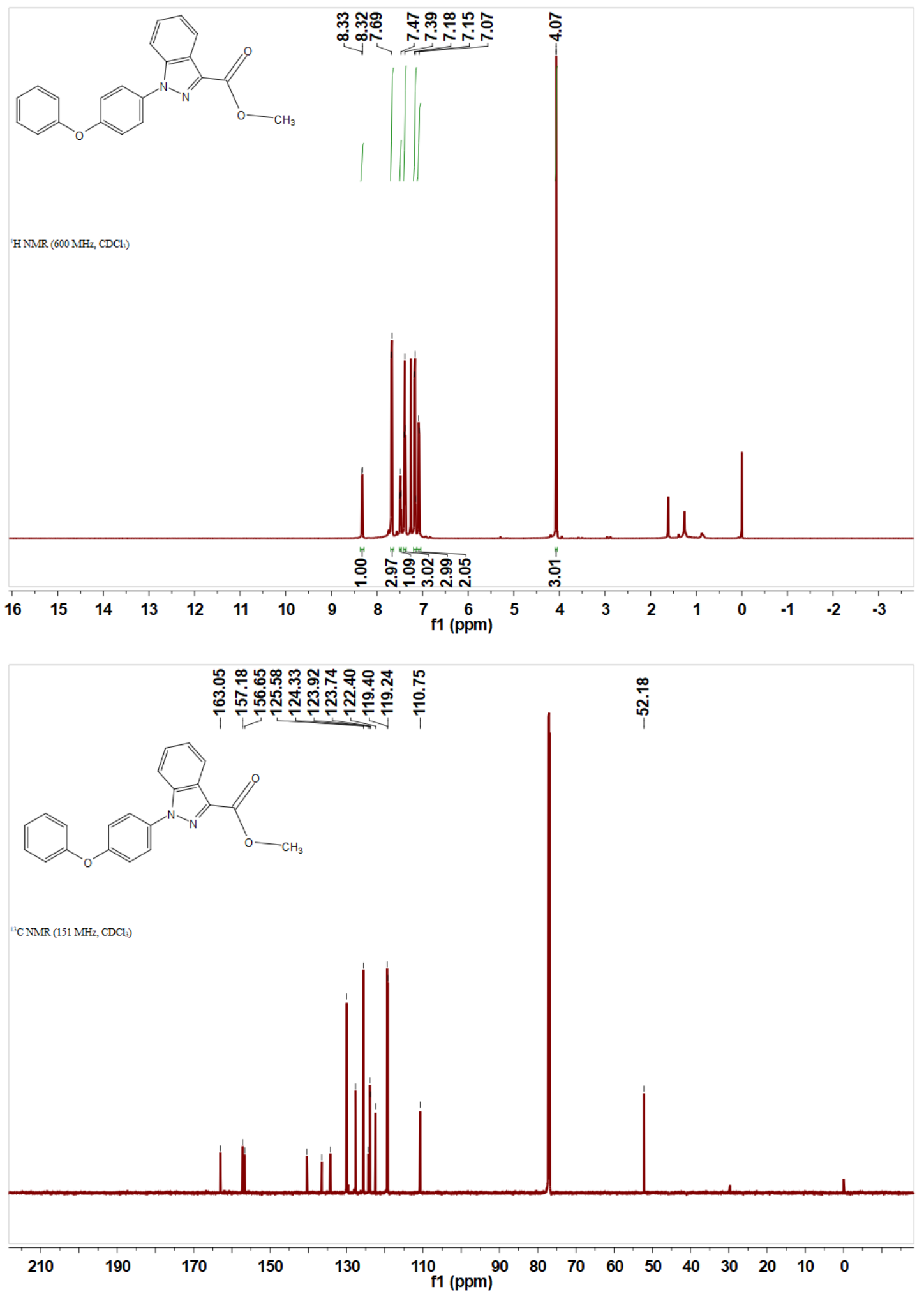

Figure S32. NMR spectra of $\mathbf{5 a}$. 

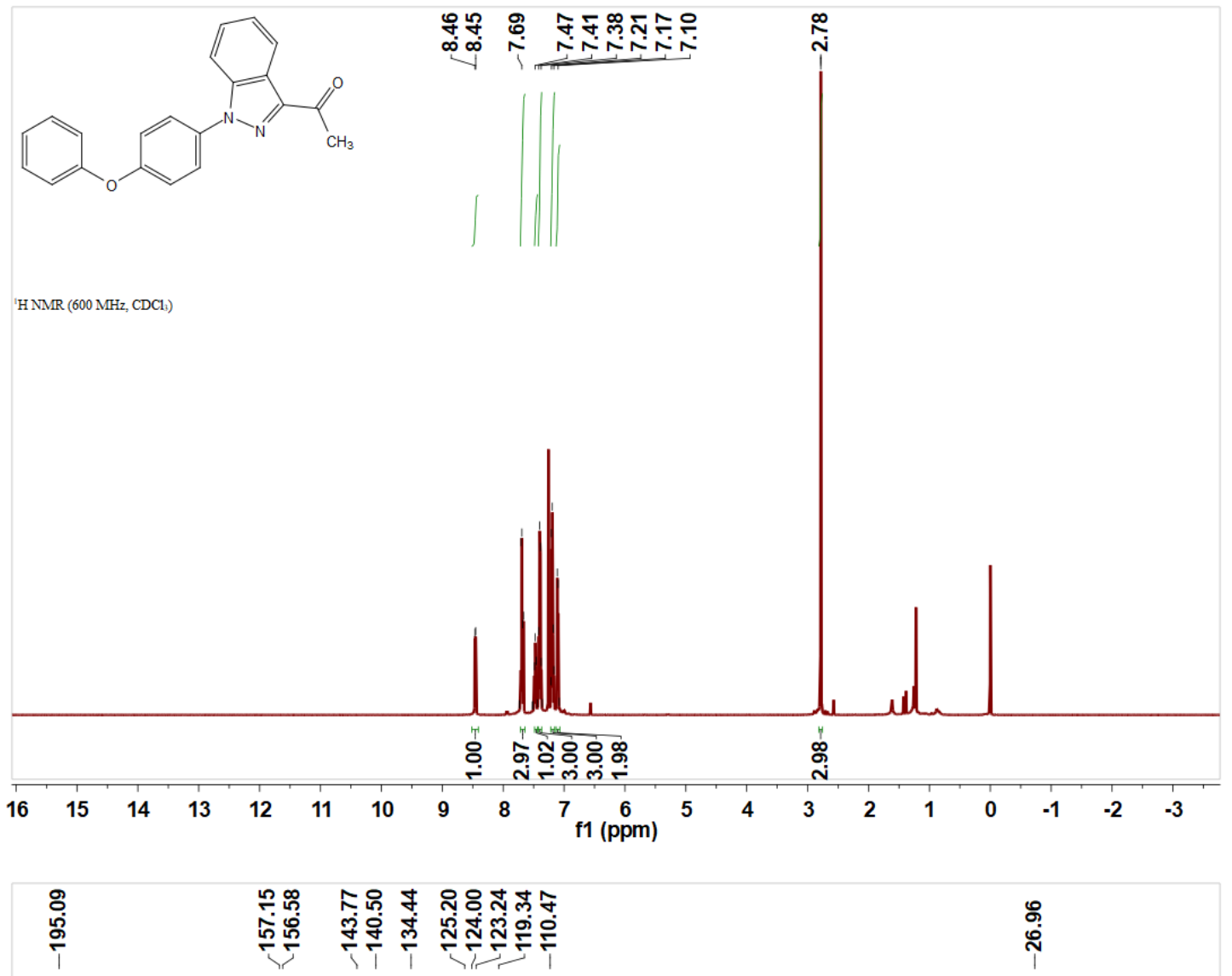

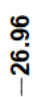

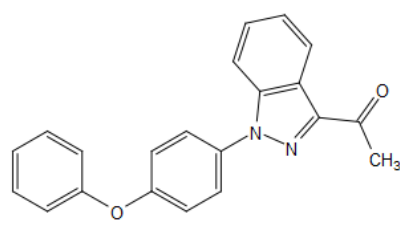

${ }^{13} \mathrm{CNMR}\left(151 \mathrm{MHz}, \mathrm{CDCl}_{1}\right)$

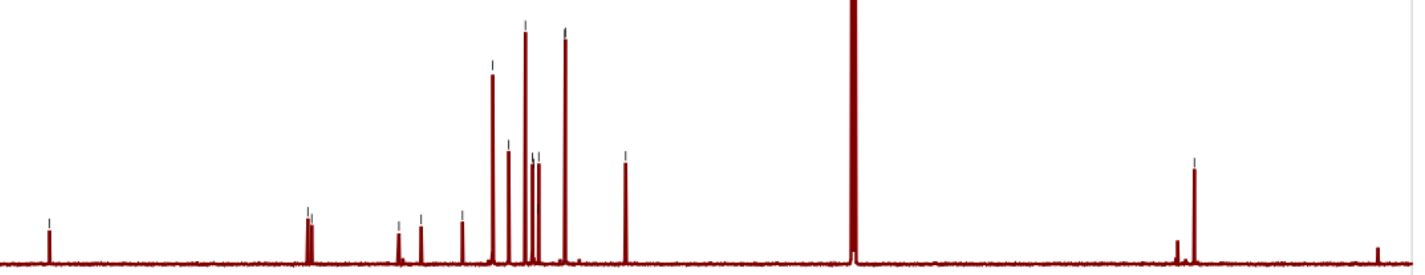

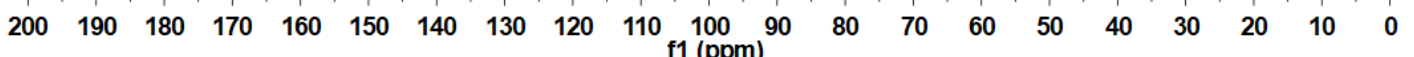

Figure S33. NMR spectra of $\mathbf{5 b}$. 

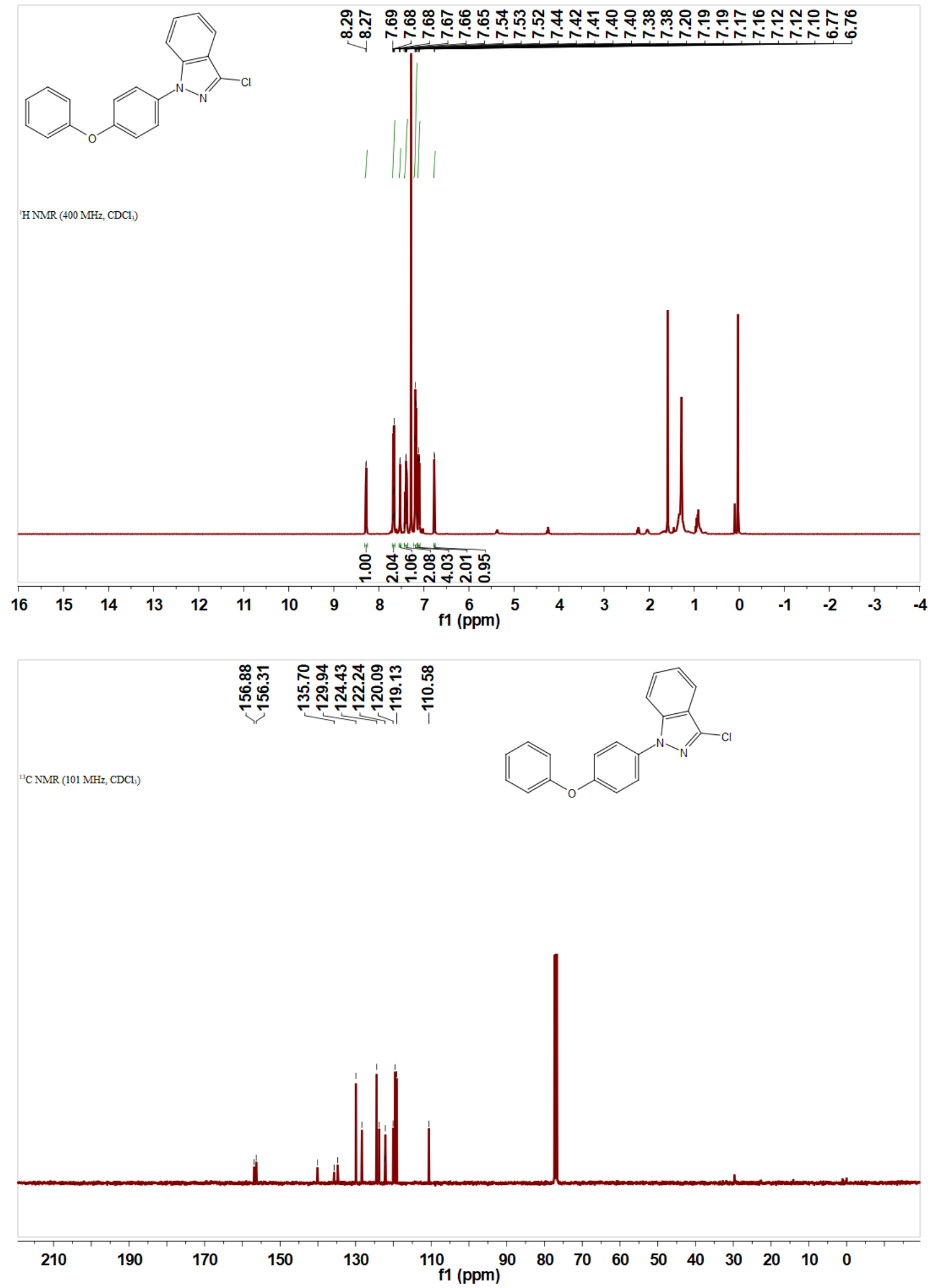

Figure S34. NMR spectra of 5c. 

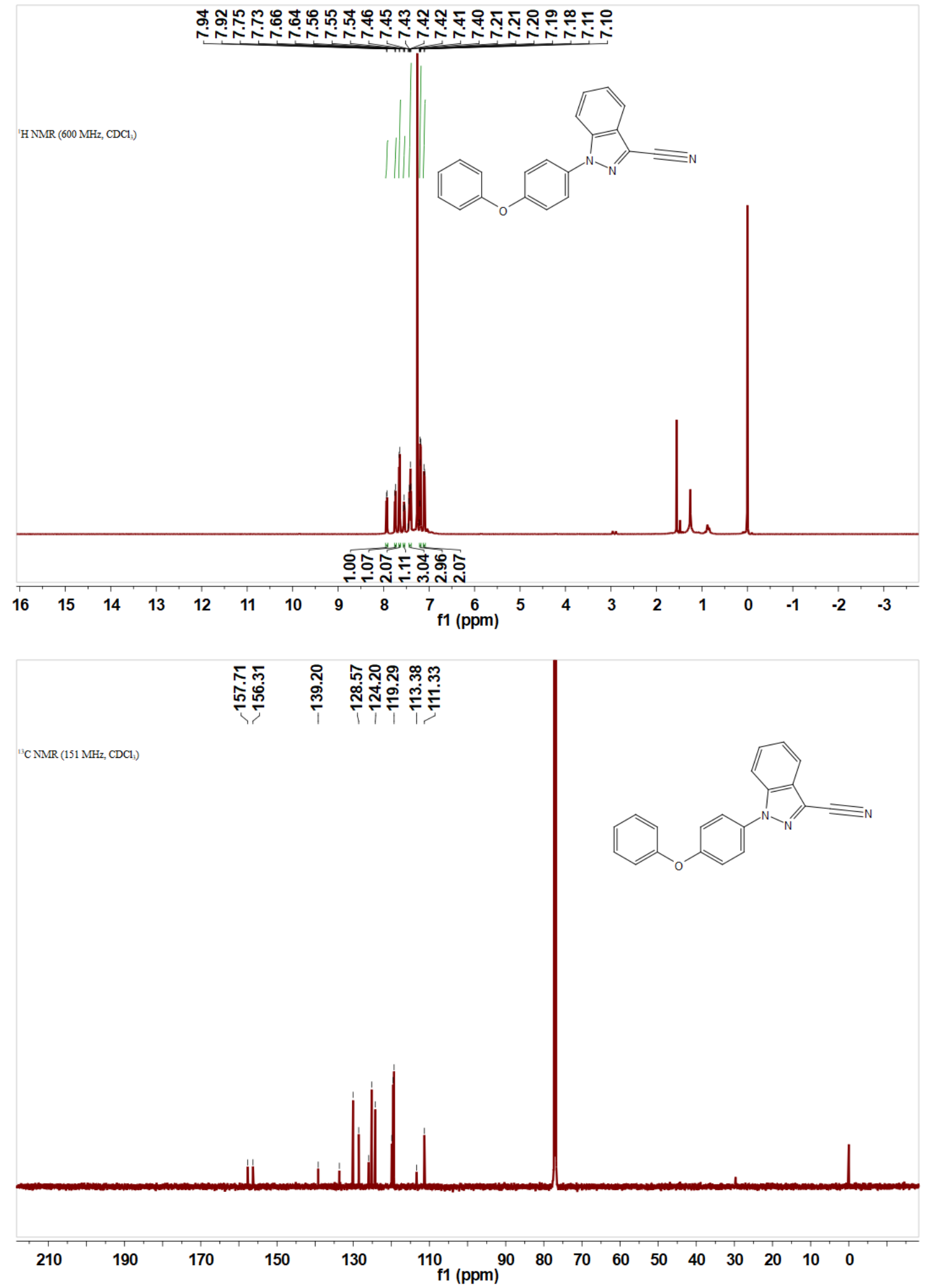

Figure S35. NMR spectra of $\mathbf{5 d}$. 


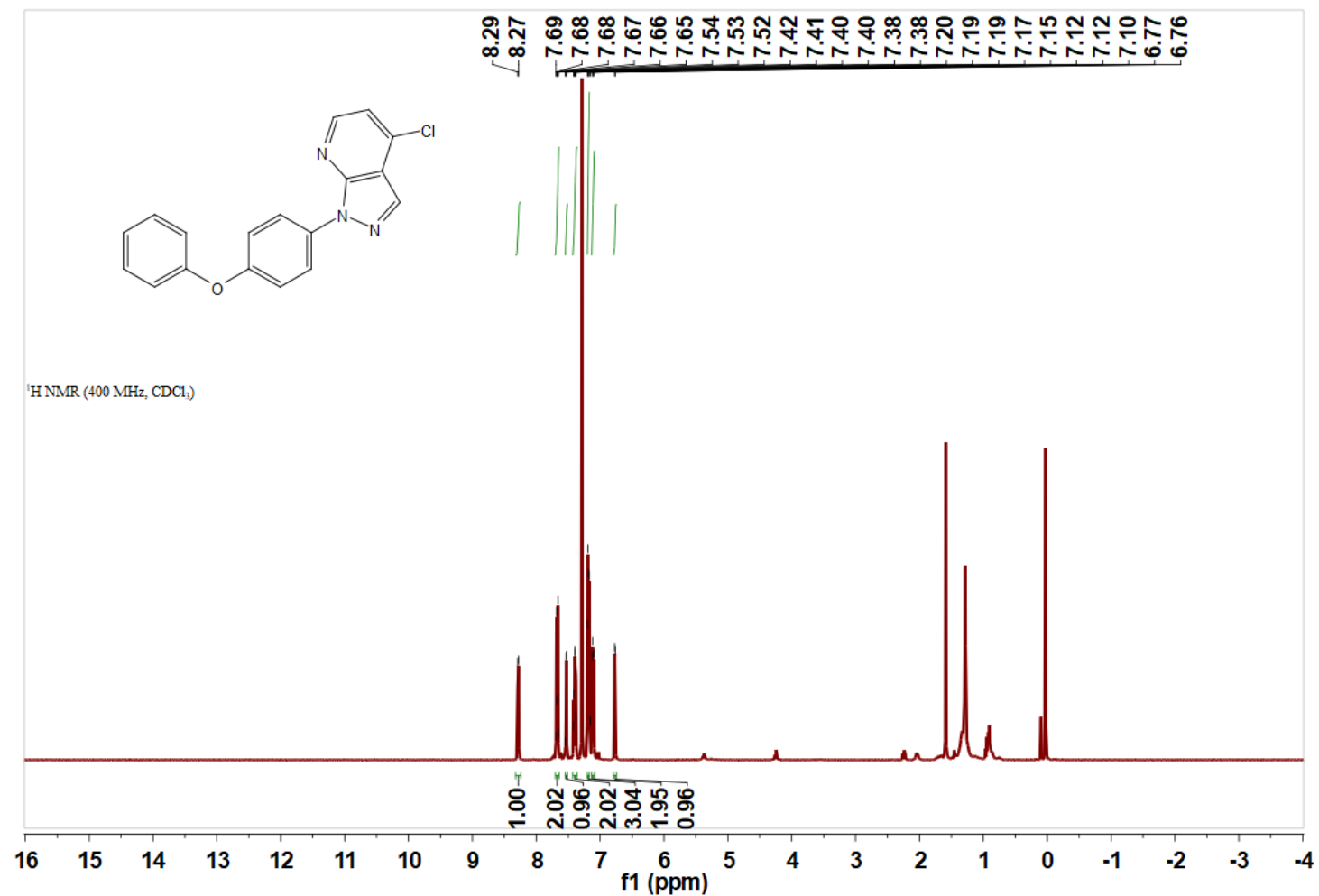

${ }^{13} \mathrm{CNMR}(101 \mathrm{MHz}, \mathrm{CDCl}$ )
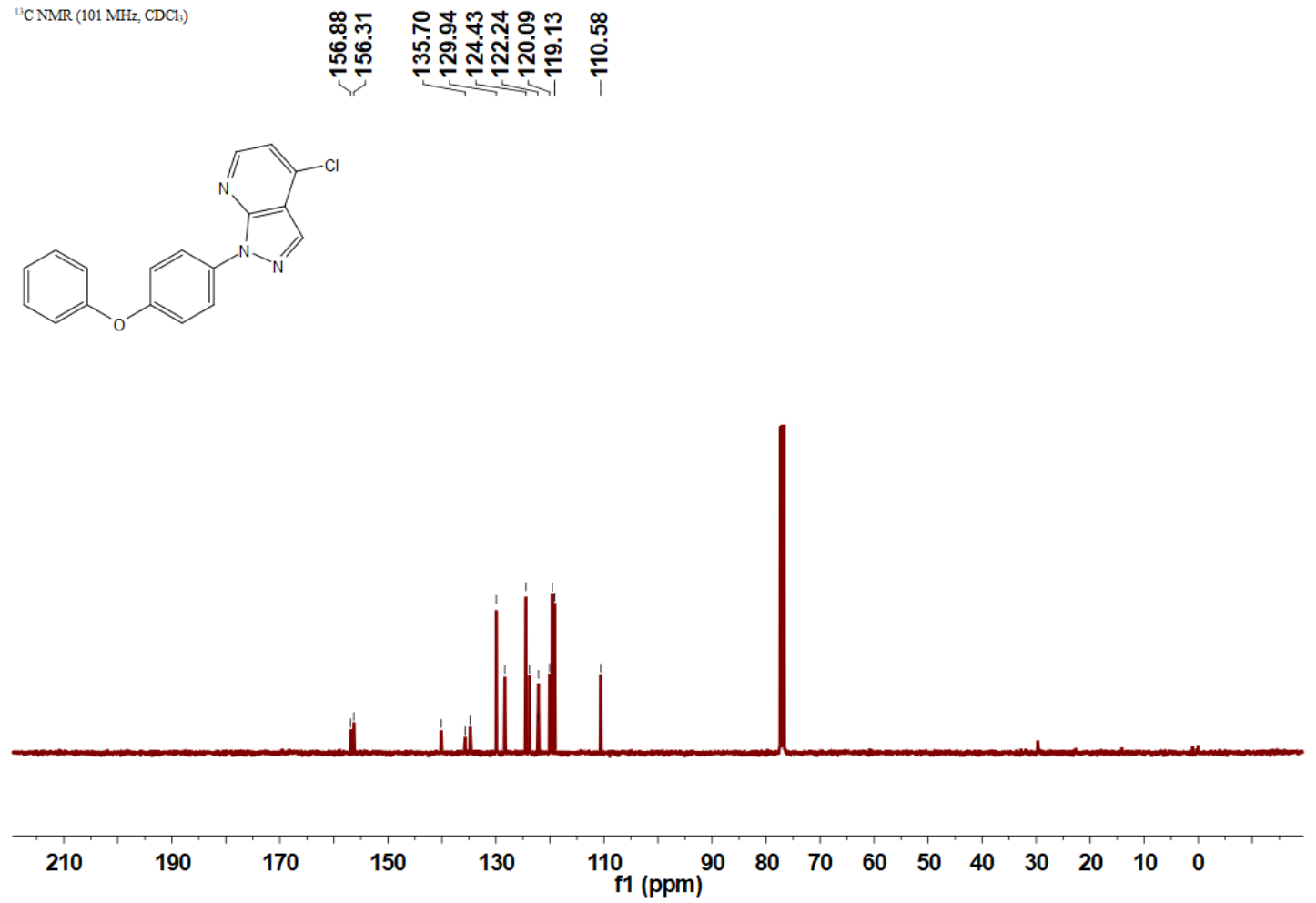

Figure S36. NMR spectra of 5 e. 

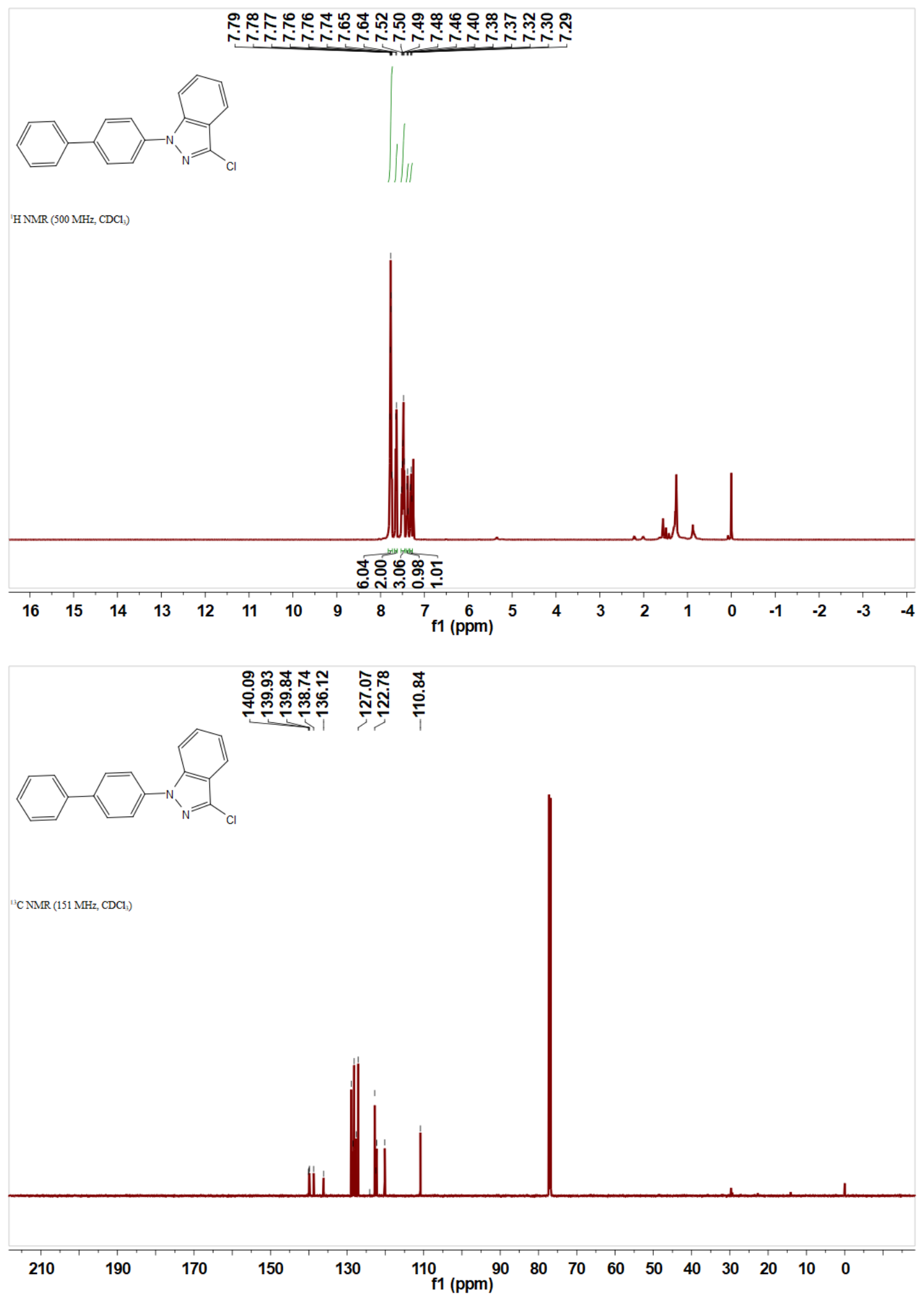

Figure S37. NMR spectra of $\mathbf{5 f}$. 

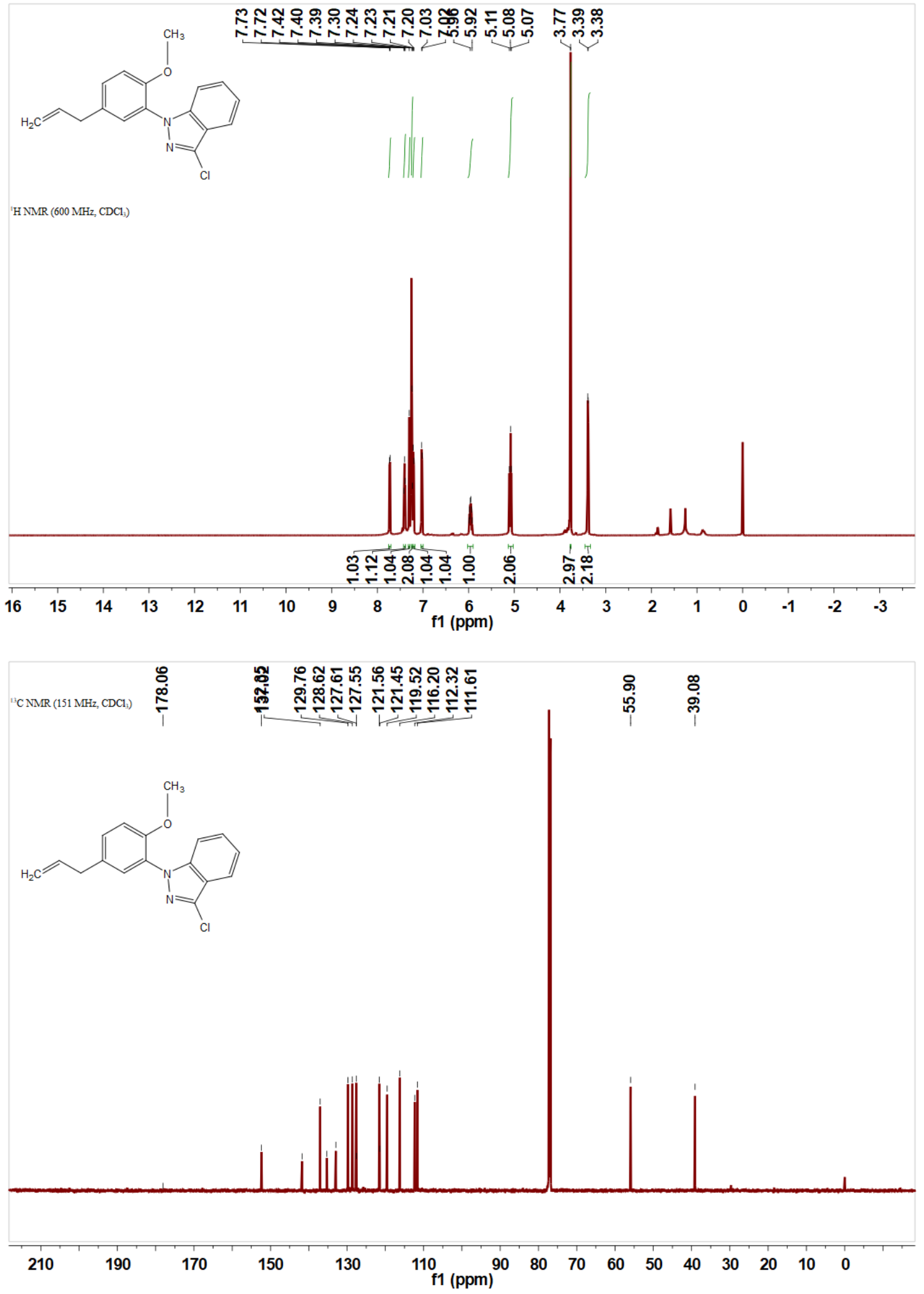

Figure S38. NMR spectra of 5g. 

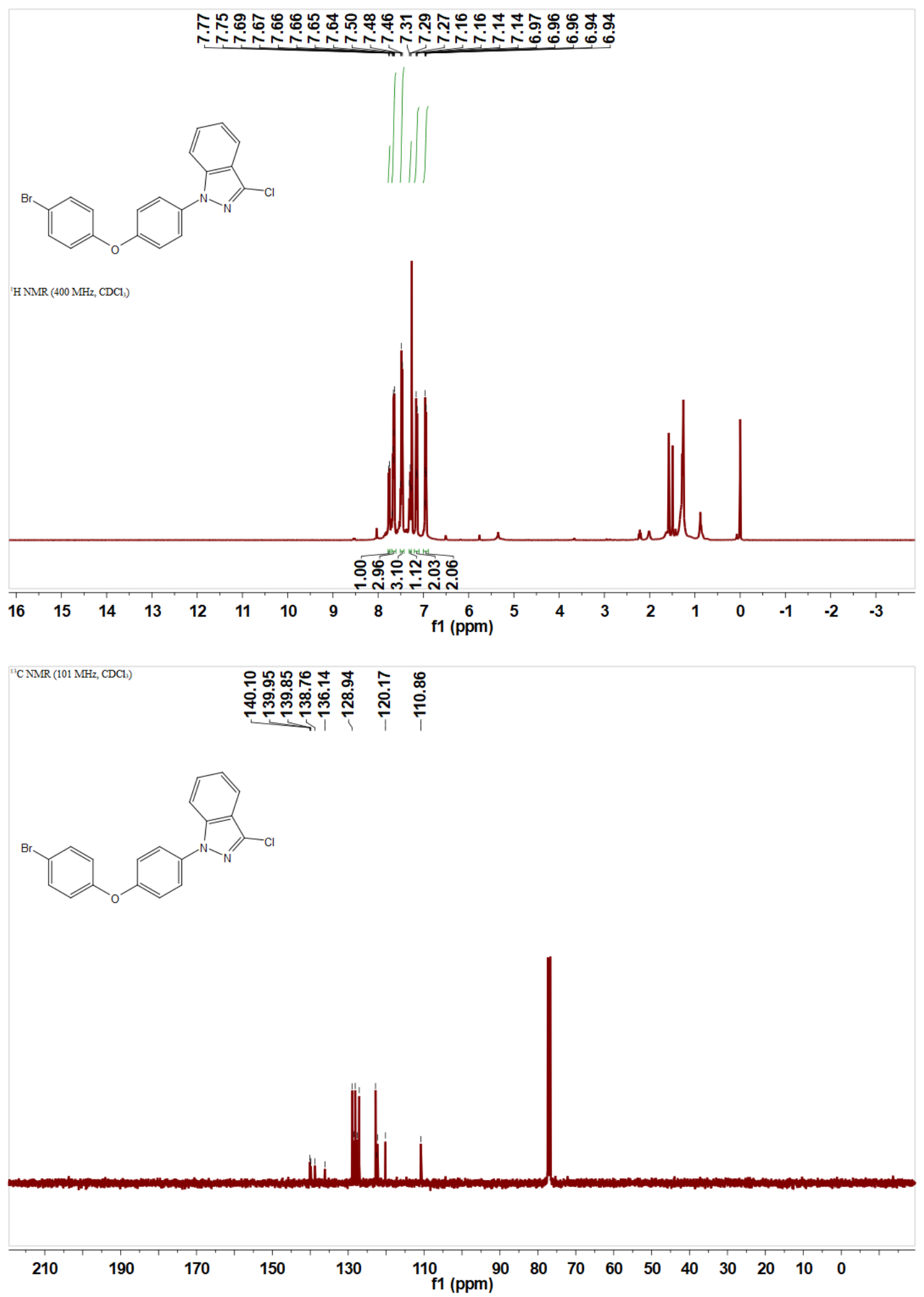

Figure S39. NMR spectra of $\mathbf{5 h}$. 


\section{References}

S1. Engl, P. S., Haring, A. P.; Berger, F., Berger, G., Perez-Bitrian, A., Ritter, T. C-N Cross-Couplings for Site-Selective Late-Stage Diversification via Aryl Sulfonium Salts. J. Am. Chem. Soc., 2019, 141, 13346-13351.

S2. Ye, F., Berger, F., Jia, H., Ford, J., Wortman, A., Bçrgel, J., Ritter, T., Aryl Sulfonium Salts for Site-Selective Late-Stage Trifluoromethylation. Angew. Chem. Int. Ed., 2019, 58, 14615-14619.

S3. SMART Data collection software (version 5.629); Bruker AXS Inc., Madison, WI, 2003.

S4. SAINT, Data reduction software (version 6.45); Bruker AXS Inc., Madison, WI, 2003.

S5. Sheldrick, G. M. Crystal structure refinement with SHELXL, Acta Crystallogr. Sect. C: Struct. Chem. 2015, 71, 3-8.

S6. Spek, A. L. Single-crystal structure validation with the program PLATON, J. Appl. Crystallogr. 2003, 36, 7-13.

S7. Li, H.; Cao, X.; Zhang, C.; Yu, Q.; Zhao, Z.; Niu, X.; Sun, X.; Liu, Y.; Ma, L.; Li, Z. Enhanced adsorptive removal of anionic and cationic dyes from single or mixed dye solutions using MOF PCN-222. RSC Adv. 2017, 7, 16273-16281. 